THE EFFECTS OF SPACE RADIATION ON MOSFET DEVICES AND SOME APPLICATION IMPLICATIONS OF THOSE EFFECTS

by

Frederick Gordon, Jr. and Harry E. Wannemacher, Jr.

NASA-Goddard Space Flight Center 


\title{
THE EFFECTS OF SPACE RADIATION ON MOSFET DEVICES AND SOME APPLICATION IMPLICATIONS OF THOSE EFFECTS by
}

\author{
Frederick Gordon, Jr. and Harry E. Wannemacher, Jr. \\ NASA-Goddard Space Flight Center
}

Introduction

The NASA-Goddard Space Flight Center is in the process of designing and building into electronic subsystems metal-oxide-semiconductor microcircuits for use in spacecraft telemetry that will be used on a number of space exploration missions. The systems design engineers are particularly attracted to these devices because of the volume/power conservation features of the devices. The first spacecraft to be flown by Goddard using these devices will be the IMP-D and the IMP-F. The first is a scientific satellite that was intended to be anchored in an orbit about the moon at an altitude of about $1000 \mathrm{~km}$; the second is a highly eccentric earth-orbiting satellite with an apogee of about $196,000 \mathrm{~km}$ and a perigee of about $197 \mathrm{~km}$. The typical orbital environment that might be anticipated by the second satellite is shown in figure 1. At the time of design of the telemetry system in which the MOSFET's will be used, a comparison was made by the systems engineers, and they found for the electronic capability they desired, within the power and space considerations imposed by the overall spacecraft design, that this class of devices (P-channel, enhancement mode MOSFE $\mathrm{T}^{\prime} \mathrm{s}$ ) was the only available that would do the job. The then available bipolar microcircuits would meet the space requirements, but not the power requirements, 
by about a 15:1 ratio. The power requirements could be met using conventional components (transistors, diodes, resistors), but not the space requirement (ratio about $8: 1$ ). So, that left the MOSFET microcircuit as the only available device meeting all the necessary requirements.

This resulted in a strong practical interest at GSFC as to how the MOSFET devices would hold up in the typical radiation environments they might see in space. This led to the general engineering study of the effects that is reported, in part, in this paper.

First, there is the general environment to be considered. The region of prime interest is cislunar space, and here the prime radiation ambient with regard to semiconductor device damage is electrons and protons. Fairly extensive information is available that indicates, with usable accuracy, the type, energy and intensities of the ambient energetic particles, so at least reasonable engineering estimates can be made as to what simulation experiments should be performed to indicate how these devices generally perform in that ambient. Figure 2 is an example of environmental information, and the uncertainty factors involved for a typical earth satellite. In this case, it is the Polar Orbiting Geophysical Observatory (POGO).

Experiment Discussion and Results

Taking into consideration the type radiation of interest and the availability of facilities, the first tests were run using two different radiation types: Co-60, gamma and $2 \mathrm{Mev}$ electrons. The devices looked at in these experiments were single transistor p-channel, enhancement-mode MOSFET's (X1004-GME). These 
initial results are summarized in Figures 3, 4, and 5. $\mathrm{Gm}$ is defined as the slope of the $\mathrm{V}_{\mathrm{G}^{-}} \mathrm{I}_{\mathrm{D}}$ curve in the active region, and the threshold voltage is defined as that gate voltage necessary to cause a drain current $\left(\mathrm{I}_{\mathrm{D}}\right)$ of 10 microamperes to flow with 20 volts on the drain terminal. The body and source connections were grounded. Enough was determined by these experiments to indicate there could be serious problems with MOSFET in a space environment. It also indicated that the condition of bias during the exposure to radiation played an important role in just how much change in threshold voltage was attained by a given exposure.

The next set of experiments were directed toward the microcircuits that were to be used in the IMP telemetry system. In this case, instead of individual MOS transistors, the microcircuit SC 1128-GME was used. This microcircuit is shown schematically in Figure 6. This device had the convenient feature that each component transistor could be evaluated individually, besides being the main microcircuit type being used in the IMP telemetry system. The environments used in these experiments were again the Co-60 and the $2 \mathrm{Mev}$ electrons, with the addition of $22 \mathrm{Mev}$ protons.

In the gamma (Co-60) experiment, nin e (9) SC 1128's were exposed, for a total of 27 MOS transistors. During the experiment, they were divided into three groups. These groups had varying bias conditions during the exposure. The first group was biased at $\mathrm{V}_{\mathrm{G}}=10 \mathrm{~V}$ and $\mathrm{I}_{\mathrm{D}}=90 \mu \mathrm{a}$, and the second group was biased at $\mathrm{V}_{\mathrm{G}}=20 \mathrm{~V}$ and $\mathrm{I}_{\mathrm{D}}=180 \mu \mathrm{a}\left(\mathrm{V}_{\mathrm{D}}\right.$ was the dependent variable ranging around one volt). The third was biased at $\mathrm{V}_{\mathrm{G}}=6 \mathrm{~V}, \mathrm{I}_{\mathrm{D}}=54 \mu \mathrm{a}$ until a threshold of 6 volts was reached; the bias was then increased to $V_{G}=10$ volts, $I_{D}-90 \mu$ antil 
threshold of 8.6 volts was reached, and then $\mathrm{V}_{\mathrm{G}}=20$ volts, $\mathrm{I}_{\mathrm{D}}=180 \mu \mathrm{a}$ was the bias value. Typical results of this experiment are shown in Figures 7 through 9. The unit number, e.g., A-7, represents an entire SC 1128. The variation among transistors for a given microcircuit with regard to the $\mathrm{v}_{\mathrm{G} \text { th }}$ (threshold voltage) was insignificant, usually less than 0.1 volt variation. Figure 7 shows the variation in threshold with gamma dose for the 10-volt bias condition. One can see $\mathrm{V}_{\mathrm{Gth}}$ increases from about 4.5 volts to 12.5 volts for 1 megarad. Figure 8 shows the results on a similar device with the 20-volt bias condition during radiation. Here one can see that a device with $\mathrm{V}_{\mathrm{Gth}}$ equal to about 4.5 volts at zero radiation; at $10^{6}$ rads, $(\mathrm{Co}-60)$ the $\mathrm{V}_{\mathrm{Gth}}$ has increased to about 15.3 volts $\left(I_{D}=10 \mu a\right)$. This increase in rate of change of threshold with increased bias is more apparent in Figure 9, where the $V_{G}-I_{D}$ bias levels were changed during the exposure period. Figure 10 shows this with a normalized gate threshold (taken as the average change of a number of samples in each group). Here it shows vividly that this bias condition difference can result in almost an additional factor of one increase in $\mathrm{V}_{\mathrm{G} \text { th }}$ at 1 megarad; about $150 \%$ increase at 10 volts bias and about $240 \%$ increase at 20 -volt bias.

During the $2 \mathrm{Mev}$ electron exposures, a somewhat different measurement circuit technique was used to measure the $\mathrm{v}_{\mathrm{Gth}}$ that simplified the data-taking procedure. This circuit is shown in Figure 11. The readings of the gate threshold voltage using this technique are high by the value of the forward drop of the emitter diode of transistor $Q$ and must be corrected for this. In this experiment, $I_{D}=100 \mu$ a was used during each exposure and $V_{G}=V_{S}$ was the desired gate bias during exposure period. $\mathrm{V}_{\mathrm{G}}$ values of 6.6 volts, 10 volts, 15 volts and 
20 volts were used during this experiment. Figure 12 shows a typical change in threshold for the 6.6 volt bias condition. Figure 13 shows this change with electron fluence for a 10-volt bias; Figure 14 for a 15-volt bias; Figure 15 for a 20volt bias. Figure 16 shows a composite picture of this bias effect on the increase in threshold as a function of fluence.

In the proton experiments (using $22 \mathrm{Mev}$ cyclotron at ORNL), the method of measuring gate threshold was similar to that used in gathering electron data. In addition, extensive use was made of the curve tracer (Tektronix 575) plots to evaluate the results of this type radiation on the MOSFET's. Figure 17 summarizes the change in threshold voltage as a function of bias during radiation. It may be seen here again that there is an increase in threshold voltage with fluence as a function of the bias applied during radiation. The similarity between these curves and those of Figures 10 and 16 is to be noted. At this point, a factor that could be an important circuit feature should be mentioned here. There might be a tendency in designers of digital circuitry using MOSFET's to use a high-bias voltage to compensate for the fact that $V_{G \text { th }}$ is continually creeping up with fluence. But inasmuch as the rate increases the harder the devices are biased on, careful consideration should be given to possibly overcompensating, causing the cure to be worse than the disease.

To indicate what a sample spread in voltage thresholds might look like in a group of MOSFET integrated circuits, Figure 18 shows the spread in 15 transistors (5 microcircuits), biased during proton radiation at 20 volts, and exposed to total fluence at $10^{12} \mathrm{p} / \mathrm{cm}^{2}(22 \mathrm{Mev})$. Figure 19 shows a composite picture of the $V_{G}-I_{D}$ curves for a device that has a threshold in the 4-5 volt range at zero 
radiation and how these curves would move out as a function of the bias applied during radiation. The total radiation in this figure is again $10^{12} \mathrm{p} / \mathrm{cm}^{2}(22 \mathrm{Mev})$. Another consideration the potential MOSFET user may be concerned with is the pre- and post-radiation dependence of the transfer curves $\left(V_{G}-I_{D}\right)$ on the drain voltage $\left(\mathrm{V}_{\mathrm{D}}\right)$. This is fairly small, as indicated in Figure 20. Figure 21 shows a typical $V_{D}-I_{D}$ curve for an SC 1128 MOSFET before and after proton $\left(10^{12} \mathrm{p} / \mathrm{cm}^{2}-22 \mathrm{Mev}\right)$ radiation. It should be noted that there is not much change in the incremental transconductance $\left(\Delta \mathrm{I}_{\mathrm{D}} / \Delta \mathrm{V}_{\mathrm{G}}\right)$ as long as you are in the saturation region. Therefore, for small signal applications, where $I_{D}$ level can be maintained by utilization of proper circuit techniques, there should be little effect on the small-signal gain of the device. However, inasmuch as this incremental transconductance is a function of $I_{D}$, if $I_{D}$ drops off, then the small-signal gm will drop. One parameter where the change factor is very noticeable, however, is in the DC transconductance $\left(\mathrm{I}_{\mathrm{D}} / \mathrm{V}_{\mathrm{G}}\right)$. This has been indicated on a number of the previous figures and is exemplified by a typical $G_{m}$ (DC) vs. $I_{D}$ curve in Figure 22. Here it may be seen that for a digital application, where a given minimum $I_{D}$ may be required to drive successive stages, the fall-off of $G_{m}(D C)$ with radiation can be quite detrimental. For example, (using Figure 22), if a minimum $\mathrm{I}_{\mathrm{D}}$ of $0.5 \mathrm{ma}\left(\mathrm{V}_{\mathrm{D}}=5\right.$ volts) were needed for the circuit, with no radiation exposure, this could be achieved with a gate voltage $\left(\mathrm{V}_{\mathrm{G}}\right)$ of about 6.8 volts, but after radiation this would require about 15.5 volts on the gate.

Now, what does this mean in terms of exposure to space radiation and what, if anything, can be done about protecting these devices, if necessary? In order to get a first cut at this problem, and to be able to use the data at hand, let us 
make several simplifying assumptions. First assumption is that the damage caused is not energy-dependent. This assumption is not really valid, as there is some strong indication of inverse electron energy dependence (Ref. 1), and there probably is a proton energy dependence. However, for this analysis, we will set aside this factor. This assumption permits us to equate the damage we get from electron and proton energies we have used in our experiments with the damage of equal numbers of electrons or protons of any energy that will be incident upon the MOSFET packages in the spacecraft. The second assumption we will make is that the damage from protons and electrons is merely additive, so that if we add the damage factor from the electrons to that of the protons, we will get a total damage factor. For our example we will assume that the operating bias condition in orbit is equivalent to a gate voltage of -20 volts.

Using these assumptions, we take the typical environment we have indicated in Figure 1 for the IMP-F satellite and show how this could affect a MOSFET (SC 1128) microcircuits. In Figure 1, we see that there is, for the epoch indicated, a total electron dose $\left(\mathrm{E}_{\mathrm{e}}>0.5 \mathrm{Mev}\right)$ of about $6 \times 10^{12} \mathrm{e} / \mathrm{cm}^{2}$-year and a total proton dose $\left(\mathrm{E}_{\mathrm{p}}>15 \mathrm{Mev}\right)$ of about $4.2 \times 10^{11} \mathrm{p} / \mathrm{cm}^{2}$-year. We will examine the change in $\mathrm{V}_{\mathrm{gth}}$ with radiation, as it is this parameter's changes which is the most pronounced with radiation, and it is a change which is reflected in change in other parameters, such as $G_{m}$ (DC). With no shielding from the spacecraft itself, you might expect (using Figures 15 and 18) that the increase in threshold voltage (initial value $\mathrm{V}_{\mathrm{Gth}}=5$ volts) due to electrons to be about 10 volts and due to protons to be about 9 volts. This would lead to a new $\mathrm{V}_{\mathrm{Gth}}$ at the end of a year of about 24 volts. This would be in most cases excessive. In a normal spacecraft of the IMP type, we would expect the electronics to get 
average shielding of the equivalent of about $0.5 \mathrm{~g} / \mathrm{cm}^{2}$ (Al). If we look at Figure 23 , we would see that this might be expected to shield out all protons below 20 Mev and all electrons below 1.25 Mev. This would bring our total electron dose incident upon our MOSFET's to $3.8 \times 10^{12} \mathrm{e} / \mathrm{cm}^{2}$-year and our protons down to $2 \times 10^{10} \mathrm{p} / \mathrm{cm}^{2}$-year. The electron-induced increase under these circumstances would now be about 9 volts and that due to protons about 1 volt, for a new threshold voltage at the end of a year of about 15 volts. While this is an improvement, it is still a 3 to 1 increase in threshold voltage. In a talk presented at the 1965 IEEE/PGNTS Conference, R. L. Van Allen (Ref. 2) had indicated the intention of NASA/GSFC systems design personnel to further shield these MOSFET packages with an additional $2 \mathrm{gm} / \mathrm{cm}^{2}(\mathrm{Al})$, an action permitted by the weight-space savings gained by use of these devices. This would bring the total shielding to about $2.5 \mathrm{~g} / \mathrm{cm}^{2}$. Referring again to Figure 23, we see we might expect all electrons with energies less than $5 \mathrm{Mev}$ and all protons with energies less than $45 \mathrm{Mev}$ to be stopped. Going back to Figure 1, we now see that this would result in about $1.7 \times 10^{11} \mathrm{e} / \mathrm{cm}^{2}$-year and $2 \times 10^{9} \mathrm{p} / \mathrm{cm}^{2}$-year. This would result in a total increase in $\mathrm{V}_{\mathrm{Gth}}$ for the year of about only 1.5 volts, which is a factor that could easily be handled for either digital or analog purposes. This discussion is summarized in Figure 24. Even taking into consideration the limitations of the oversimplifying assumptions made in this analysis, two general factors may be observed. First, that the MOSFET's represented in these experiments can only be used in typical space mission, such as represented by IMP, if proper shielding and circuit design precautions are observed; but even with these limitations, can be used in situations where space-power-weight considerations for desired electronic performance are warranted. However, it becomes apparent that a 
great deal of improvement in device radiation resistance is desirable, and efforts are being supported in this direction by GSFC and others.

One approach to this problem of improved radiation resistance in insulatedgate field-effect transistors is using different materials, particularly for the insulator. One of the prime motivating factors for using this approach is the volume of evidence that has been compiled by numerous investigators that indicates that the charge build-up in the oxide of MOS-FETs, when exposed to a radiation environment is a prime cause of the effects we observe. (If another insulating material were used, it is possible that it would not be as susceptible to charge introduction by radiation.) This does not preclude the improvement of the silicon oxide devices, but is only exploring one possible approach to the problem. In this connection, we recently set out to compare some of the radiation performance of the metal-silicon nitride-silicon devices against two types of MOS-FETs. These devices were all p-channel, enhancement types. The MOS-FET types that were used were the FI-100 (Fairchild) and the MM2103 (Motorola). The latter is a fairly low $\mathrm{V}_{\mathrm{gth}}(0)$ device, with high transconductance. The FI-100 is a lower transconductance device and was not too dissimilar in initial characteristics from the MNS-FETS used in the experiment. The MNSFETs used were fabricated by Sperry. The particular MNS devices available for this experiment had somewhat high $\mathrm{V}_{\mathrm{gth}}(0)$ ranging up to over 9 volts. No attempt is made here to make any physical analysis of the results only to report changes in device characteristics and briefly discuss some of the engineering potentialities and implications. 
Because of the number of MNS devices available, only nine (9) devices per type were used in the comparison experiment. They were divided into three (3) groups. Each group had a different applied bias during the experiment $(0,-10$, -20 volts). The radiation environment used were $1.5 \mathrm{MeV}$ electrons.

Figures 25, 26, \& 27 show the variation (increase) in $\mathrm{V}_{\mathrm{gth}}$ with radiation dose. These are plots of individual devices, but are typical of the trends. Figure 25 is with zero bias applied radiation; Figure 26 with -10 volts applied and Figure 27 with -20 volts. These devices are biased in the direction they might normally be in operation. As has been shown in the first part of this paper on the SC-1128 MOS-FET, here too there is this strong dependence on bias. However, it is to be observed that the MNS devices change relatively little during this irradiation out to $5 \times 10^{12}$ electrons $/ \mathrm{cm}^{2}$, while there are appreciable changes in $\mathrm{V}_{\text {gth }}$ for the other devices, particularly the MM2103. But it should also be noted that the MM2103's start at much lower $\mathrm{V}_{\mathrm{gth}}$ and the operational comparison factors only became really pertinent after the cross-over points.

Figures 28,29 \& 30 show transconductance curves at the three different bias levels for the three device types. These curves are shown at zero radiation, $10^{12} \mathrm{e} / \mathrm{cm}^{2}$ and $5 \times 10^{12} \mathrm{e} / \mathrm{cm}^{2}$. There are a number of factors that can be observed here of interest to the MIS-FET user. The general observations indicated in the first part of this paper with regard to bias dependence and circuit design consideration still hold. The incremental transconductance (Gm AC) is only very slightly affected by the radiation. The change in threshold voltage is the main cause of the operational changes of the device in the circuit. This includes the $\mathrm{DC}$ transconductance $\left(\mathrm{I}_{\mathrm{D}} / \mathrm{V}_{\mathrm{G}}\right)$. As pointed out previously, inasmuch 
as $\mathrm{Gm}(\mathrm{AC})$ is function of $\mathrm{I}_{\mathrm{D}}$, in a situation where $V_{D}$ and $V_{G}$ are fixed, $\mathrm{Gm}(\mathrm{AC})$ will drop because $I_{D}$ decreases with increasing radiation dose. However, if the $\mathrm{V}_{\mathrm{G}}$ can be varied to maintain $\mathrm{I}_{\mathrm{D}}$, then $\mathrm{Gm}(\mathrm{AC})$ will change very little. To get back to comparison between the three type devices, it may be seen that the DC transconductance is very little changed in the case of the MNS-FET, radically changed in case of the MM2103 and appreciably changed with the FI-100. Figures 31,32 and 33 show this graphically where GM(DC) is plotted against $I_{D}$ zero dose and $5 \times 10^{12}$ electrons $/ \mathrm{cm}^{2}$. Figures 34,35 and 36 show the differential Gm for these same devices $\left(\delta I_{D} / \delta V_{G}\right) V_{D}=K$. The shape and magnitude of these curves change very little for a given device, as a function of radiation fluence. Also of interest to the potential user of these devices is that where the $\mathrm{Gm}(\mathrm{DC})$ of the device is low, the drain current, $\mathrm{I}_{\mathrm{D}}$, can only be driven out so far for any reasonable value of $\mathrm{Vg}$ and this current limitation is further aggravated by exposure to radiation. The principal observation that results from this comparison test is that MNS-FET devices, with acceptable initial electronic characteristics, show relatively little change with exposure to radiation such as might be encountered in space. Therefore, we feel that this nitride insulator approach is a promising solution to the MIS-FET radiation susceptability problem.

After having run the comparison tests out to $5 \times 10^{12} \mathrm{e} / \mathrm{cm}^{2}$, and getting a good indication of the relative performance of the three types, it was decided to run the MNS devices in the test out to $10^{15} \mathrm{e} / \mathrm{cm}^{2}$. The overall change seemed to be relatively low, but some anomalous behavior was observed. Figures 37 , 38 , and 39 show the behavior in this region. The scale is amplified to exaggerate this effect, which generally is a dip in the curve followed by an increase. However, 
this dip does not start at the same dose for every device, even within a single bias group. The flux rate was higher during this run, than during the comparison runs; $10^{12} \mathrm{e} / \mathrm{cm}^{2}-\mathrm{sec}$ as opposed to $10^{10} \mathrm{e} / \mathrm{cm}^{2}-\mathrm{sec}$. To see if there was possibly something associated with the experiment that might have caused the anomalies, the three extra MNS-FETs we had were biased at -20 volts and run out to fluences of $5 \times 10^{15} \mathrm{e} / \mathrm{cm}^{2}$ (at $10^{11} \mathrm{e} / \mathrm{cm}^{2}-\mathrm{sec}$ to $10^{14} \mathrm{e} / \mathrm{cm}^{2} ; 10^{12} \mathrm{e} / \mathrm{cm}^{2}-$ sec to $10^{15} \mathrm{e} / \mathrm{cm}^{2}$ ) (Figure 40). Here again we saw the same anomalous behavior but, no identical fluence level initiation pattern or any specific fluence - minimum $\mathrm{V}_{\text {gth }}$ point. The general increase-decrease pattern was observed in all. It does not seem to be flux-rate dependent within flux variations of this experiment, although this is possible, with its thermal implications. However, the overall increase in $\mathrm{V}_{\mathrm{gth}}$, even out to $5 \times 10^{15}$ and -20 volts bias, is in the worst case only about $17 \%$.

\section{CONCLUSIONS}

The general conclusions that can be made from these experiments are as follows:

1. Even with the radiation susceptibility of the earlier MOS-FET devices, they can be used in spacecraft applications with proper shielding. This shielding can be tolerated because of the space-weight-power savings made possible by use of MOS-FETs in the telemetry circuitry of interest.

2. MNS-FETs are a promising approach to making MIS-FET devices more radiation tolerant, and efforts should be and are being promoted to develop these devices for this purpose; and at perhaps looking at other insulator materials, as well. 
3. The newer MOS-FET's (e.g. MM2103), with their lower initial gate threshold voltages and higher transconductances, can be used advantageously in selected radiation environment applications (see Figures 25-30 out to doses $\sim 5 \times 10^{11} \mathrm{e} / \mathrm{cm}^{2}$ ). A careful examination of initial and post-radiation characteristics should be made by applications engineers planning to use MIS-FET's in a space radiation environment to see what trade-offs can be made in performance, change of parameters with radiation, shielding, etc.

4. Much more physical and engineering data collection and analysis is needed on all MIS-FET devices in order that both the device fabricator and the applications engineer can each do his job more effectively in developing and selecting insulated-gate devices for use in space radiation environments.

\section{References}

1. K. H. Zaininger, Applied Physics Letters, Vol. 8, \#6, March 15, 1966.

2. R. L. Van Allen, Design Considerations in Radiation Hardening of Telemetry and Control Circuitry in Spacecraft (1965 IEEE Annual Conference on Nuclear and Space Radiation Effects, University of Michigan). 


\section{AVERAGE RADIATION FLUXES FOR HIGH ECCENTRICITY ORBIT SATELLITE (IMP)}

Incl $33^{\circ}$
Apogee $19,000 \mathrm{~km}$
Perigee $\quad 195 \mathrm{~km}$
Period $93.33 \mathrm{hrs}$.

Electrons

\begin{tabular}{cl} 
Energy band (MeV) & $\mathrm{e} / \mathrm{cm}^{2}-$ orbit \\
\hline $0.5-1.0$ & $2.24 \times 10^{10}$ \\
$1.0-2.0$ & $2.56 \times 10^{10}$ \\
$20-3.0$ & $1.03 \times 10^{10}$ \\
$3.0-4.0$ & $3.35 \times 10^{9}$ \\
$4.0-5.0$ & $1.19 \times 10^{9}$ \\
$5.0-6.0$ & $4.59 \times 10^{8}$ \\
$6.0-7.0$ & $1.81 \times 10^{8}$ \\
$7.0-$ & $1.25 \times 10^{8}$ \\
\hline Total & $6.36 \times 10^{10} \mathrm{e} / \mathrm{cm}^{2}$ - orbit \\
& $5.98 \times 10^{12} \mathrm{e} / \mathrm{cm}^{2}$ - year
\end{tabular}

Protons

\begin{tabular}{cc} 
Energy band (MeV) & Protons $/ \mathrm{cm}^{2}$ - orbit \\
\hline $15-20$ & $4.33 \times 10^{9}$ \\
$20-25$ & $5.72 \times 10^{7}$ \\
$25-30$ & $1.09 \times 10^{7}$ \\
$30-35$ & $5.85 \times 10^{6}$ \\
$35-40$ & $3.39 \times 10^{6}$ \\
$40-45$ & $2.04 \times 10^{6}$ \\
$45-50$ & $1.26 \times 10^{6}$ \\
$50-60$ & $1.31 \times 10^{6}$ \\
$60-70$ & $5.61 \times 10^{5}$ \\
$70-80$ & $2.53 \times 10^{5}$ \\
$80-90$ & $1.19 \times 10^{5}$ \\
$90-100$ & $5.72 \times 10^{4}$ \\
$100-$ & $6.22 \times 10^{4}$ \\
\hline & $4.41 \times 10^{9} \mathrm{P}^{4} \mathrm{~cm}^{2}$ - orbit \\
& $4.16 \times 10^{11} \mathrm{P} / \mathrm{cm}^{2}$-year
\end{tabular}

Figure 1

\section{DAILY RADIATION DOSE POGO ORBIT EPOCH - JAN. 1965}

$$
\begin{array}{lrr}
\text { Protons: } & 4-12 \mathrm{MeV} & 1.85 \times 10^{8} \\
\text { (P/cm2-day) } & >30 \mathrm{MeV} & 2.5 \times 10^{7}
\end{array}
$$

Incl. $90^{\circ}$

Perigee : $370 \mathrm{~km}$

Apogee $=1120 \mathrm{~km}$

\begin{tabular}{clll}
$\begin{array}{c}\text { Electrons: } \\
\text { (e/cm2 - day) }\end{array}$ & Injun III Decay & APL - 38 C Decay & $\begin{array}{c}\text { No Decay } \\
\text { (AFTER NOV 1962) }\end{array}$ \\
\hline $0.5-1.0 \mathrm{MeV}$ & $1.66-5.05 \times 10^{10}$ & $0.99-3.07 \times 10^{10}$ & $1.02-2.96 \times 10^{11}$ \\
$1.0-2.0 \mathrm{MeV}$ & $0.72-1.76 \times 10^{10}$ & $0.35-0.87 \times 10^{10}$ & $1.14-2.74 \times 10^{11}$ \\
$2.0-3.0 \mathrm{MeV}$ & $1.04-2.5 \times 10^{10}$ & $0.51-1.26 \times 10^{10}$ & $2.16-5.21 \times 10^{11}$ \\
$3.0-4.0 \mathrm{MeV}$ & $3.68-8.69 \times 10^{9}$ & $1.77-4.31 \times 10^{9}$ & $0.84-2.01 \times 10^{11}$ \\
$4.0-5.0 \mathrm{MeV}$ & $4.08-9.51 \times 10^{8}$ & $1.95-4.66 \times 10^{8}$ & $0.95-2.27 \times 10^{10}$ \\
$5.0-6.0 \mathrm{MeV}$ & $1.39-3.24 \times 10^{8}$ & $0.66-1.59 \times 10^{8}$ & $3.23-7.75 \times 10^{9}$ \\
$6.0-7.0 \mathrm{MeV}$ & $0.46-1.06 \times 10^{8}$ & $2.18-5.21 \times 10^{7}$ & $1.06-2.53 \times 10^{9}$ \\
$7.0-8.0 \mathrm{MeV}$ & $0.93-2.17 \times 10^{7}$ & $0.45-1.06 \times 10^{7}$ & $2.21-5.31 \times 10^{8}$ \\
\hline Total & $0.385-1.03 \times 10^{11}$ & $2.05-5.69 \times 10^{10}$ & $0.53-1.32 \times 10^{12}$ \\
& & &
\end{tabular}

Figure 2 
GATE THRESHOLD VOLTAGE vs. TOTAL EXPOSURE

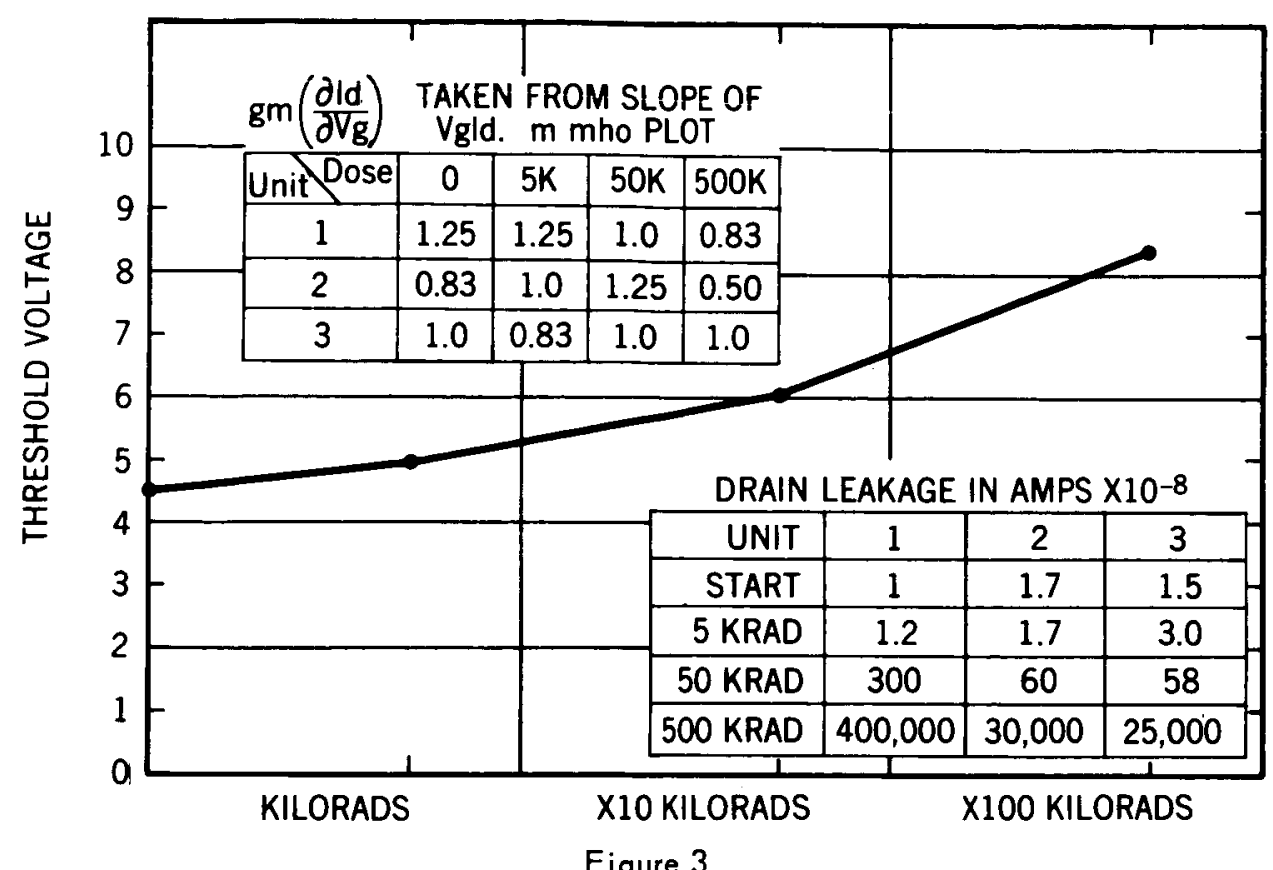

NORMALIZED GATE VOLTAGE vs. TOTAL EXPOSURE

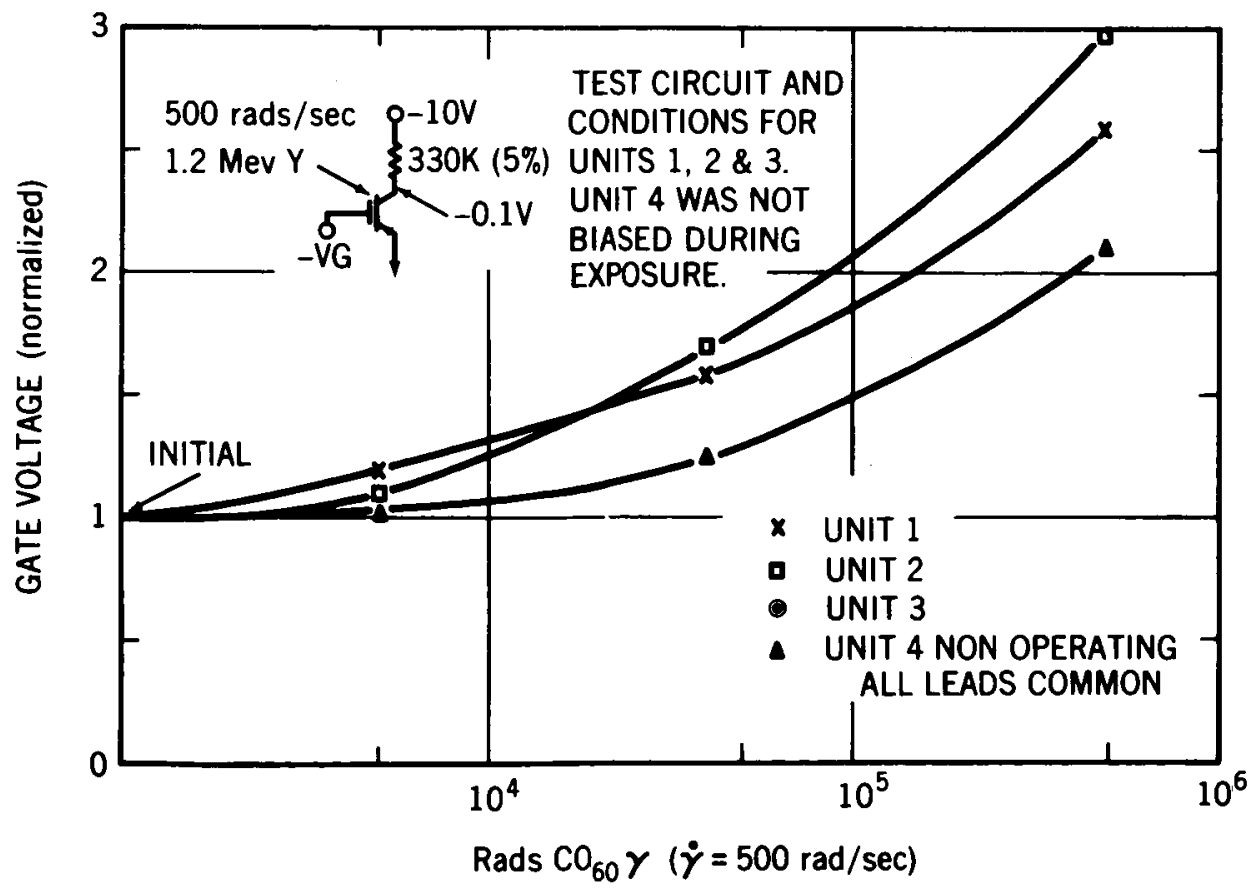

Figure 4 


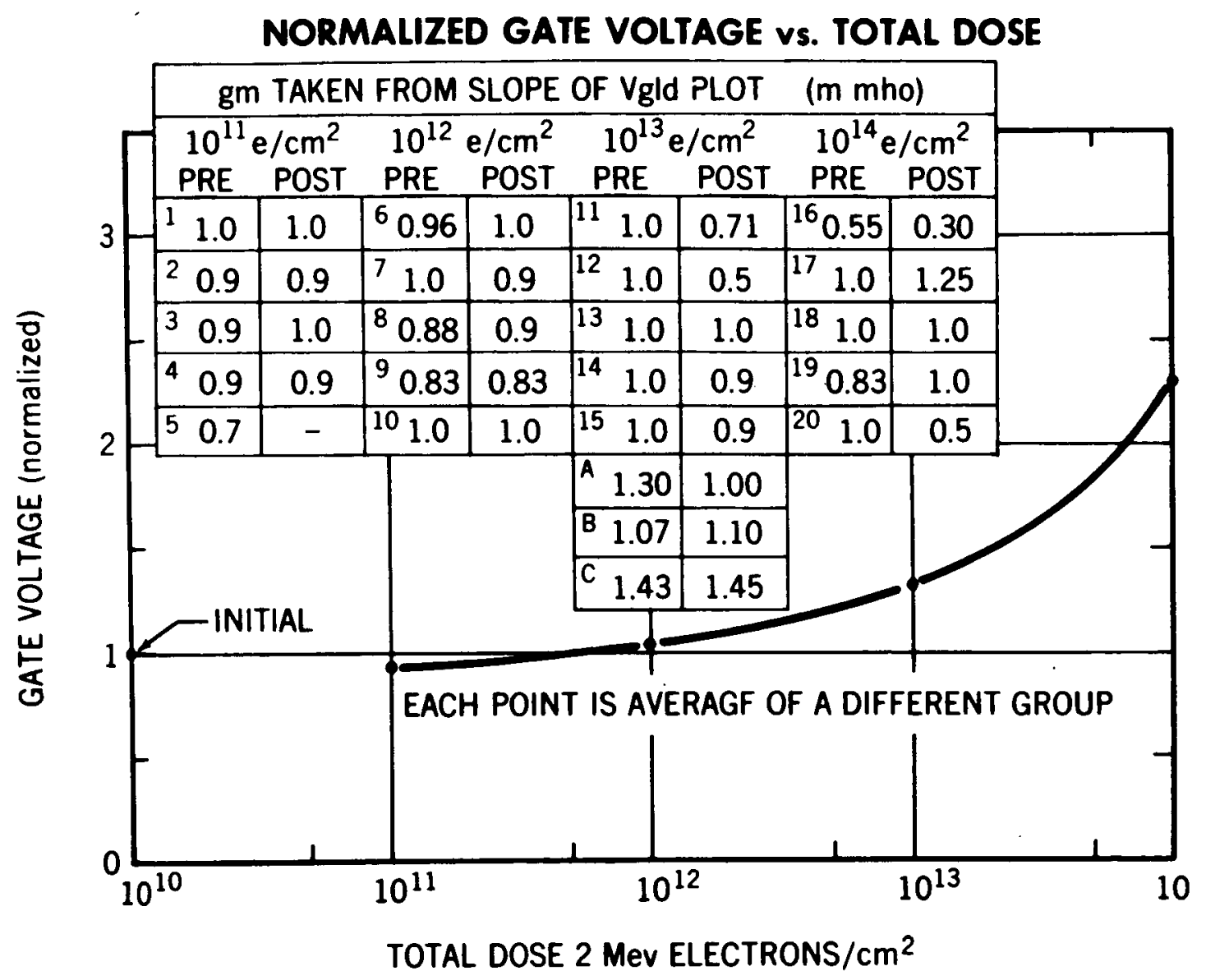

Figure 5

SCHEMATIC DIAGRAM OF LOGIC ELEMENT

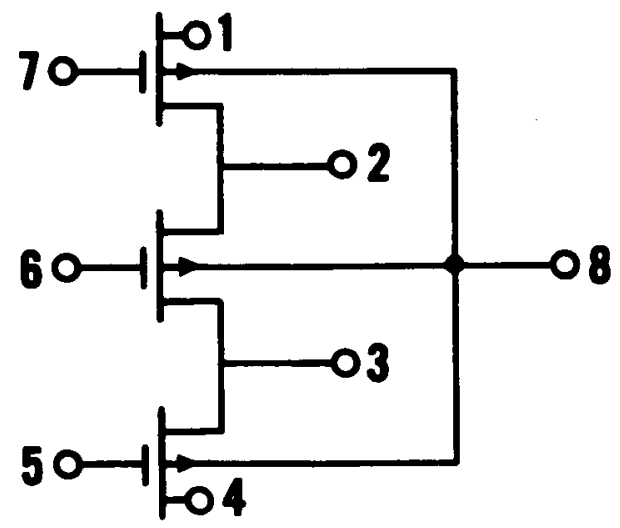

Figure 6 
UNIT A7 10 VOLTS GATE BIAS $90 \mu$ a DRAIN CURRENT DURING EXPOSURE

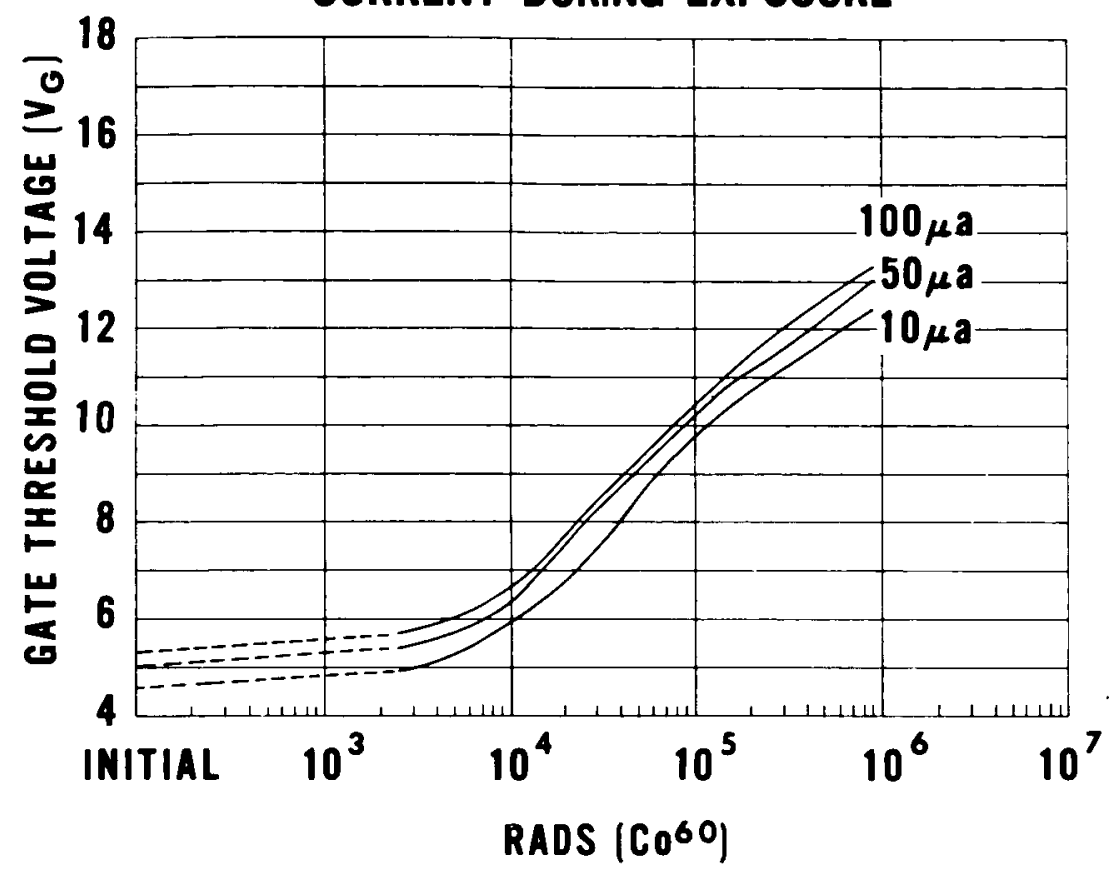

Figure 7

UNIT A3 20 VOLTS GATE BIAS $180 \mu a$ DRAIN CURRENT DURING EXPOSURE

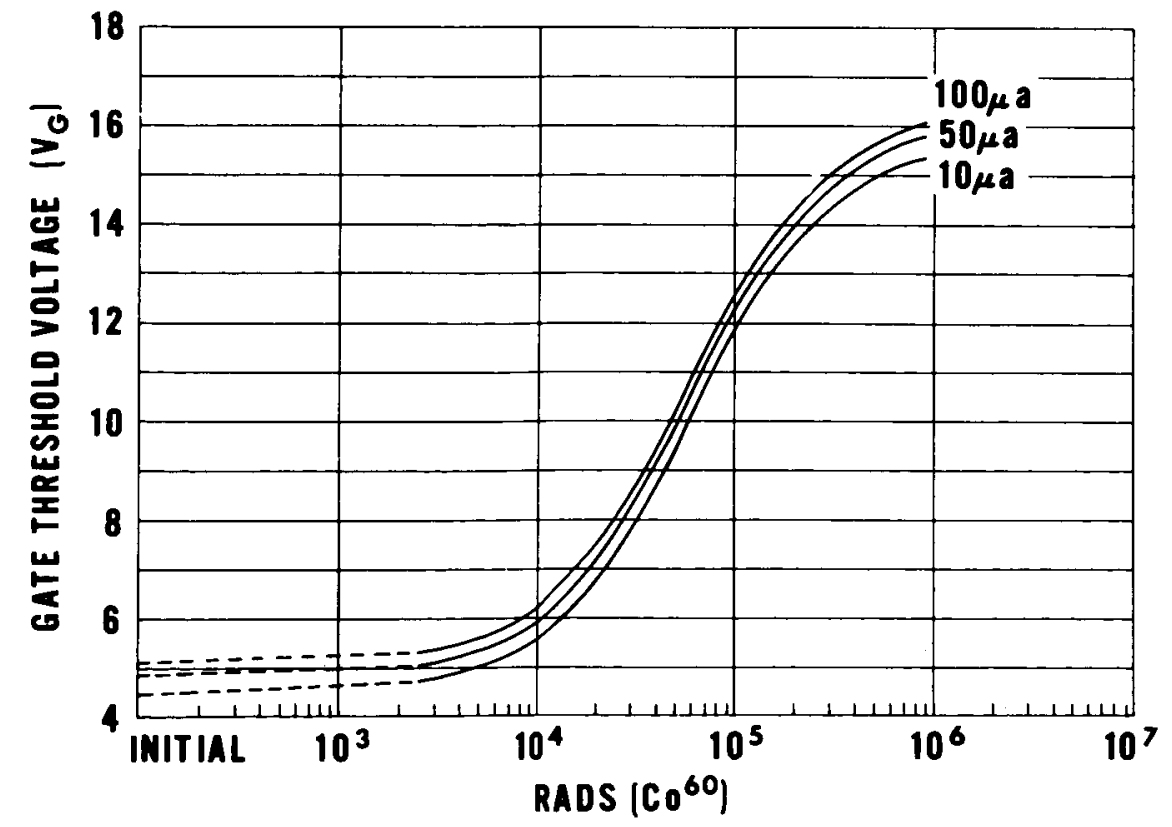

Figure 8 


\section{UNIT AB VOLTAGE BY DIFFERENT PORTIONS OF CURVE INDICATE BIAS DURING EXPOSURE}

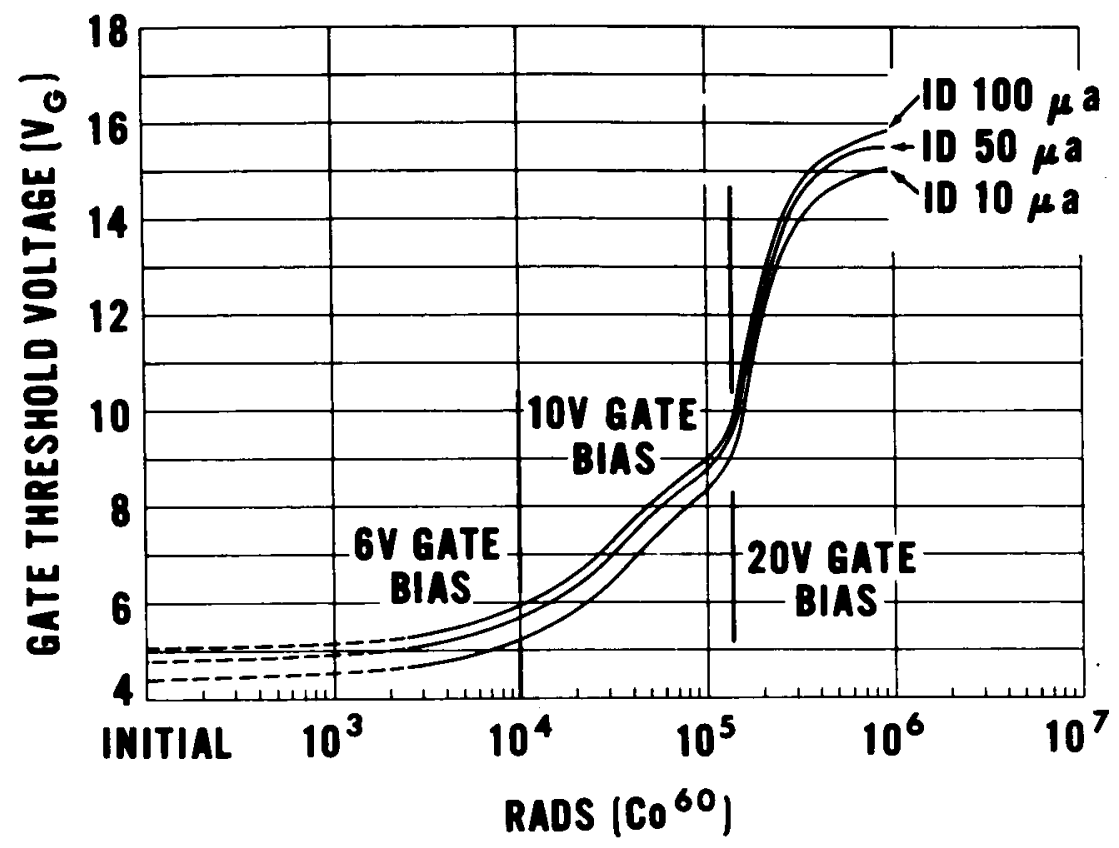

Figure 9

GATE THRESHOLD VS. DOSE WITH TWO BIASES

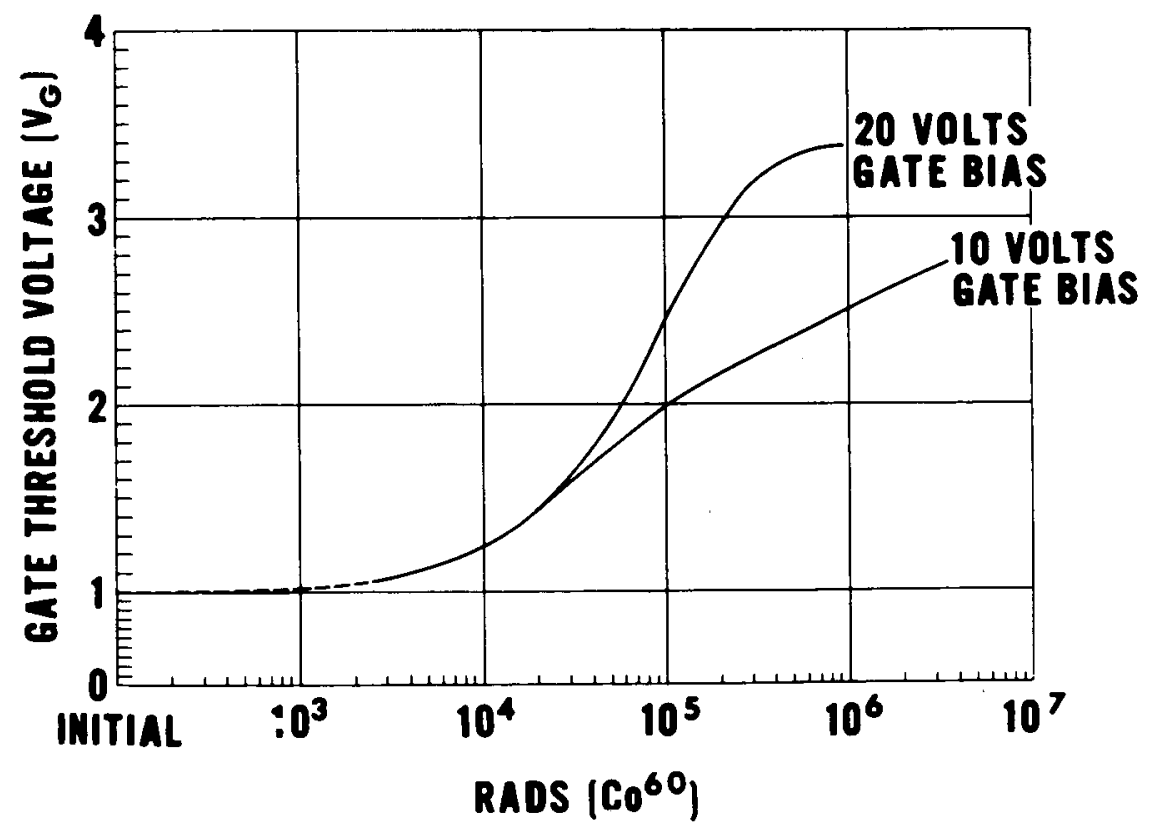

Figure 10 
GATE THRESHOLD TEST CIRCUIT

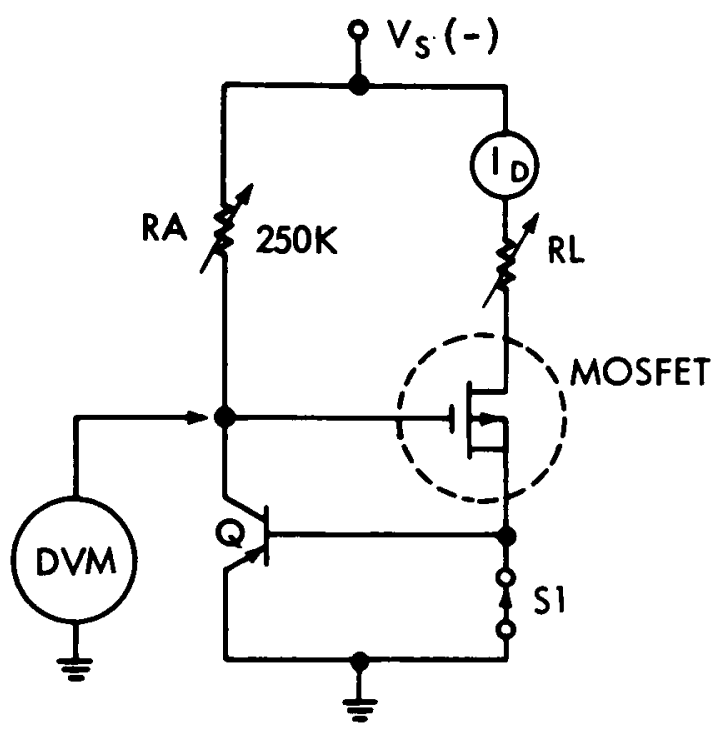

Figure 11

\section{UNIT B4 (SC1129) 6.5 V GATE BIAS DURING EXPOSURE} $100 \mu$ a DRAIN CURRENT DURING EXPOSURE

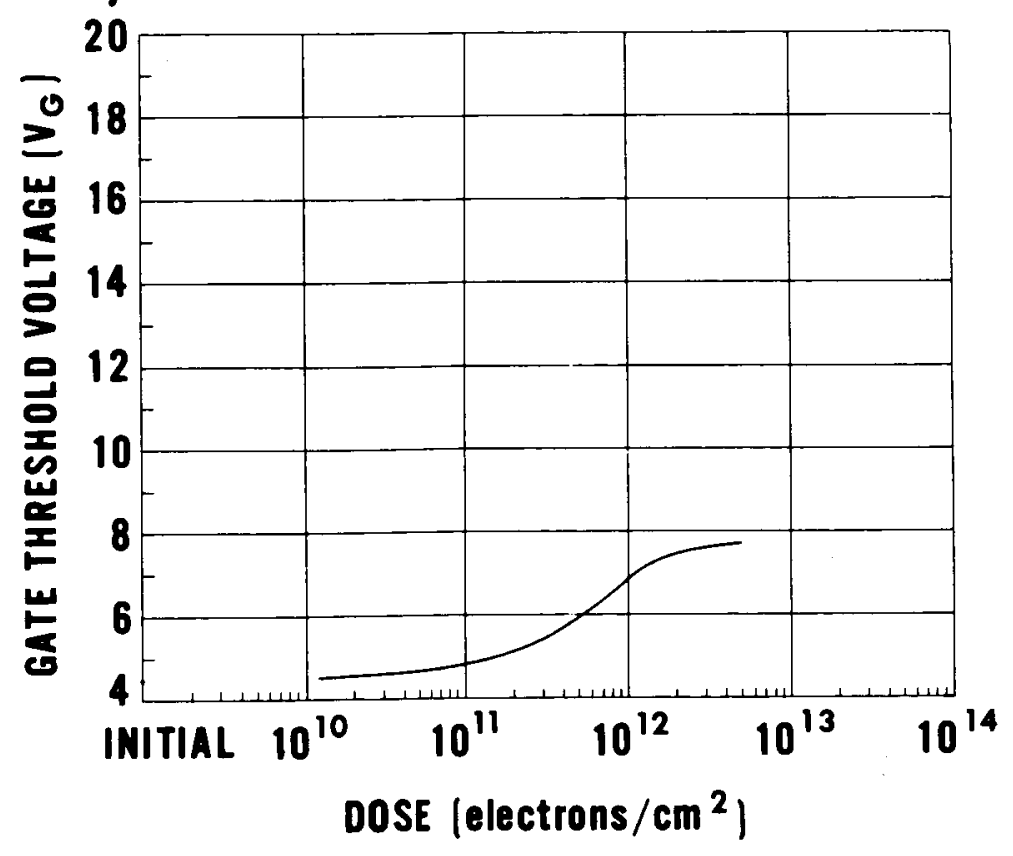

Figure 12 
UNIT B14 10 V GATE BIAS DURING EXPOSURE $100 \mu$ a DRAIN CURRENT DURING EXPOSURE.

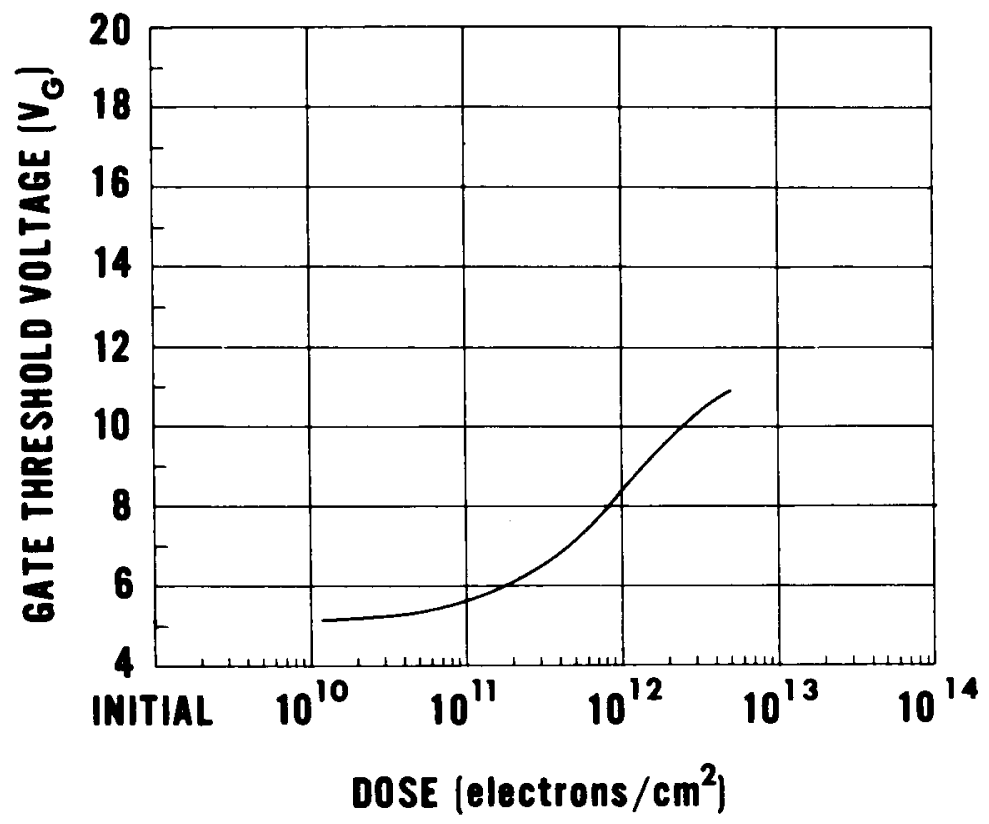

Figure 13

UNIT B11 15 V GATE BIAS DURING EXPOSURE $100 \mu \mathrm{a}$ DRAIN CURRENT DURING EXPOSURE.

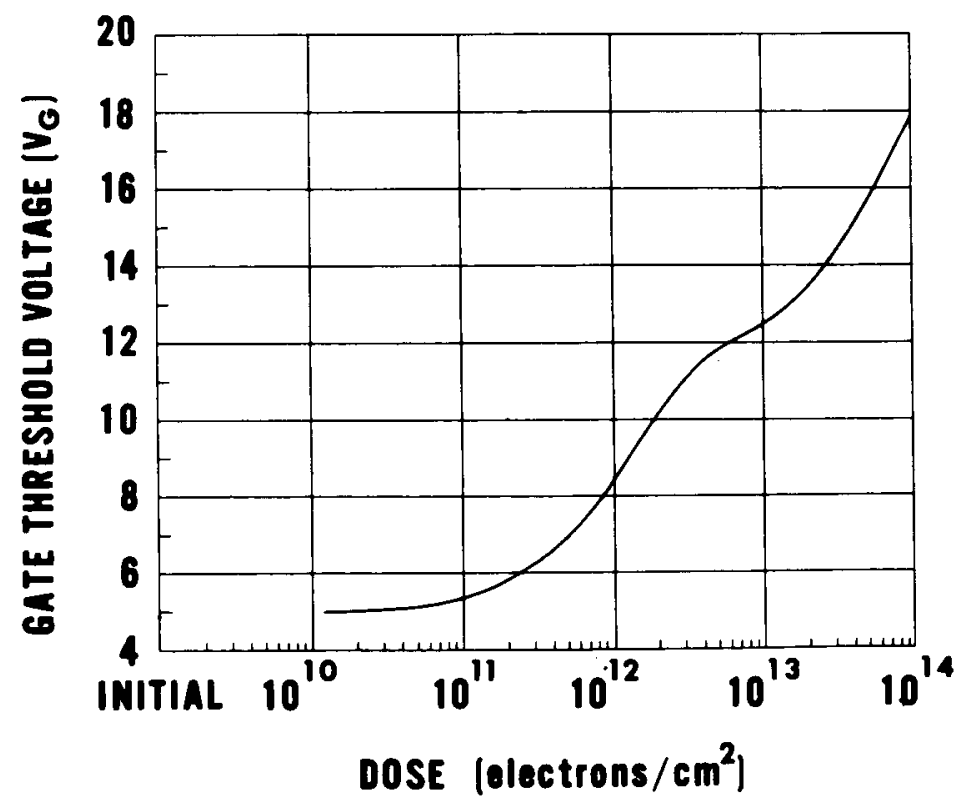

Figure 14 


\section{UNIT B8 $20 \mathrm{~V}$ GATE BIAS DURING EXPOSURE $100 \mu$ D DRAIN CURRENT DURING EXPOSURE.}

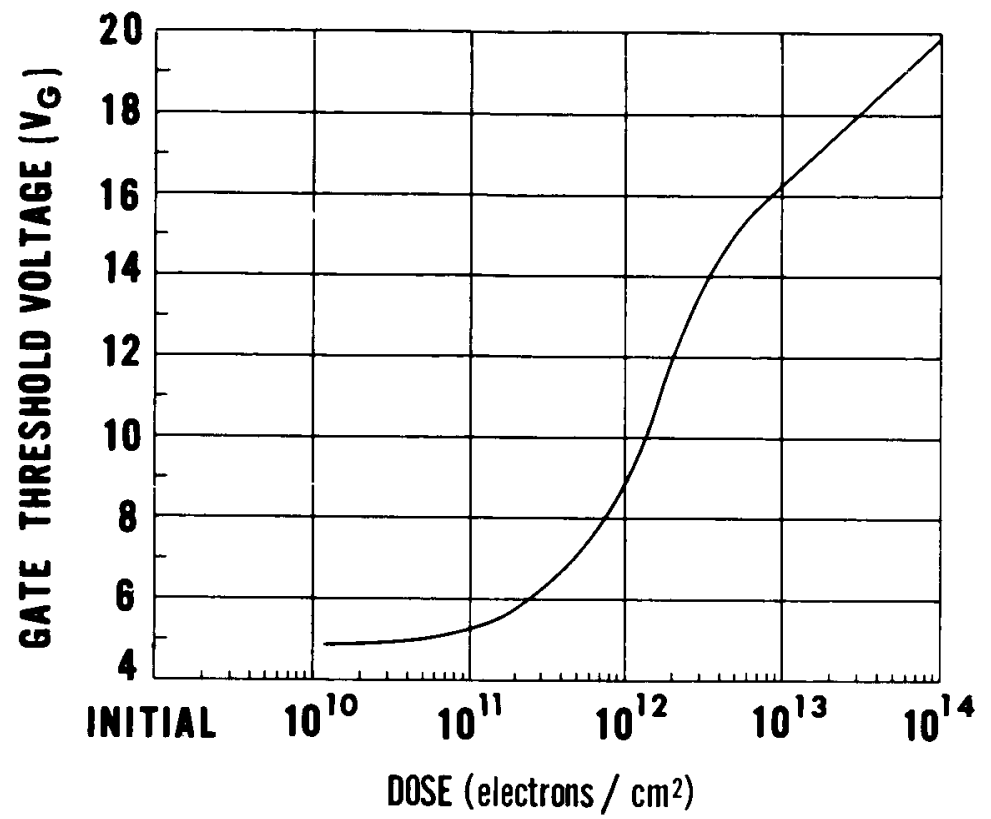

Figure 15

\section{TYPICAL NORMALIZED GATE THRESHOLD VOLTAGE VS \\ DOSE WITH GATE BIAS DURING EXPOSURE INDICATED}

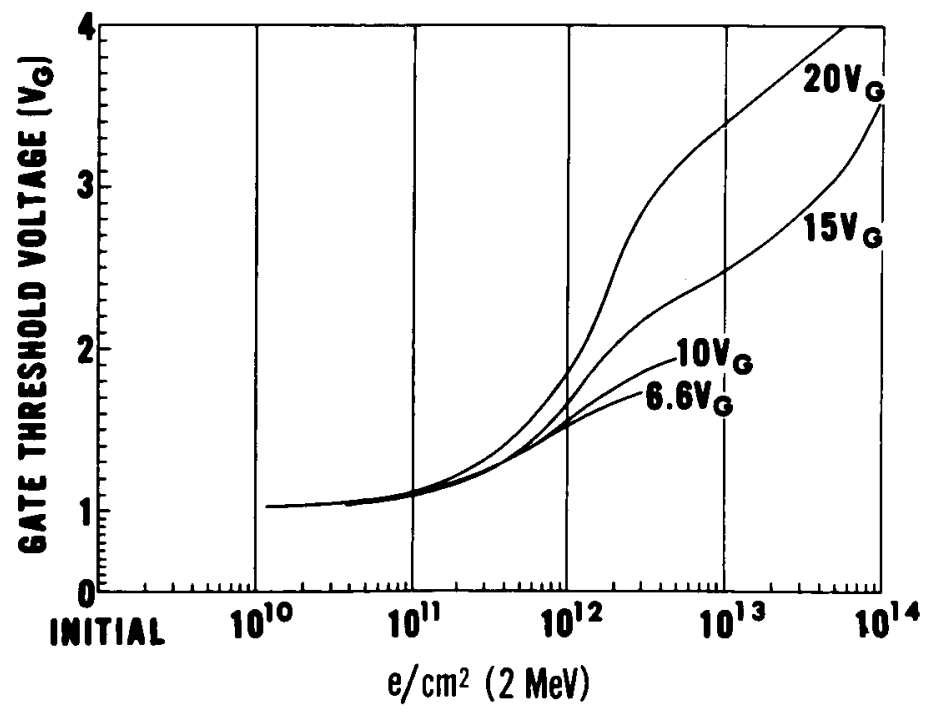

Figure 16 
TYPICAL NORMALIZED GATE THRESHOLD VOLTAGE VS PROTON DOSE

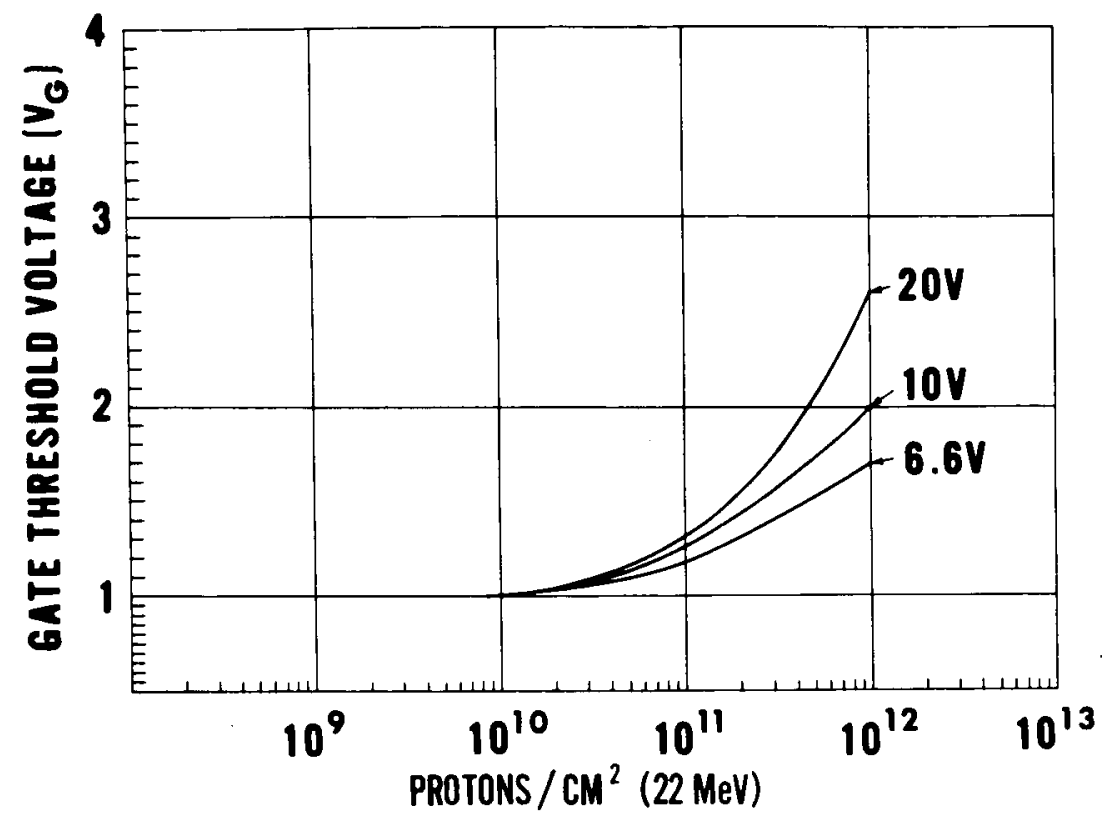

Figure 17

\section{$V_{\text {gth }}$ SPREAD OF 5 EACH SCl128}

(15 individual devices)

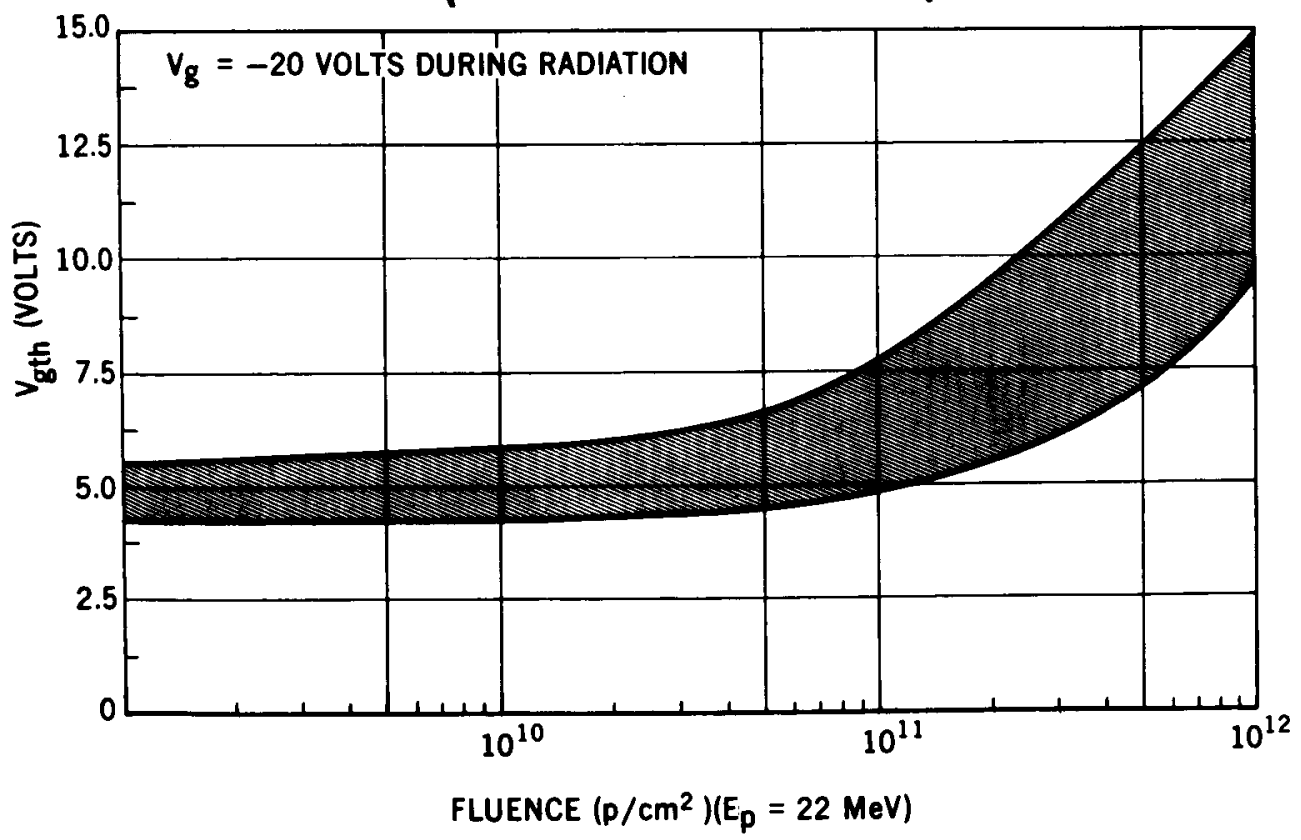

Figure 18 


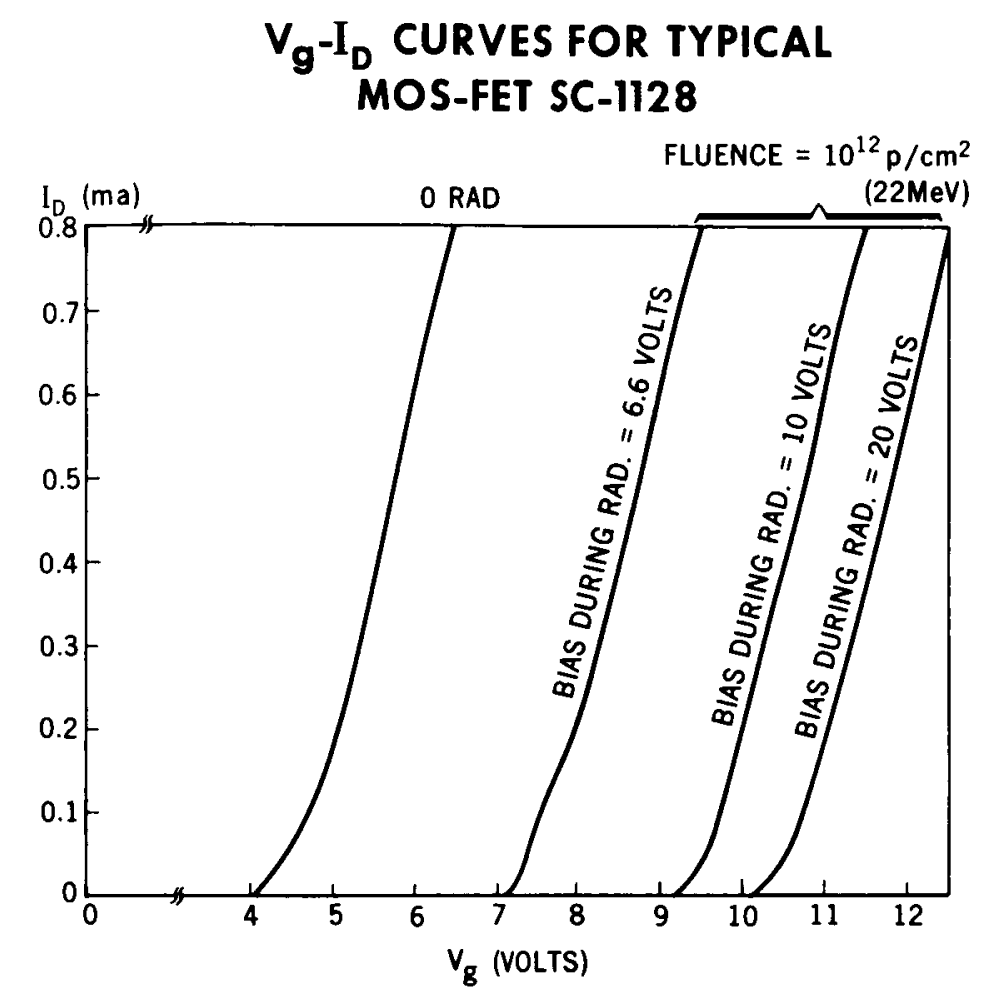

Figure 19

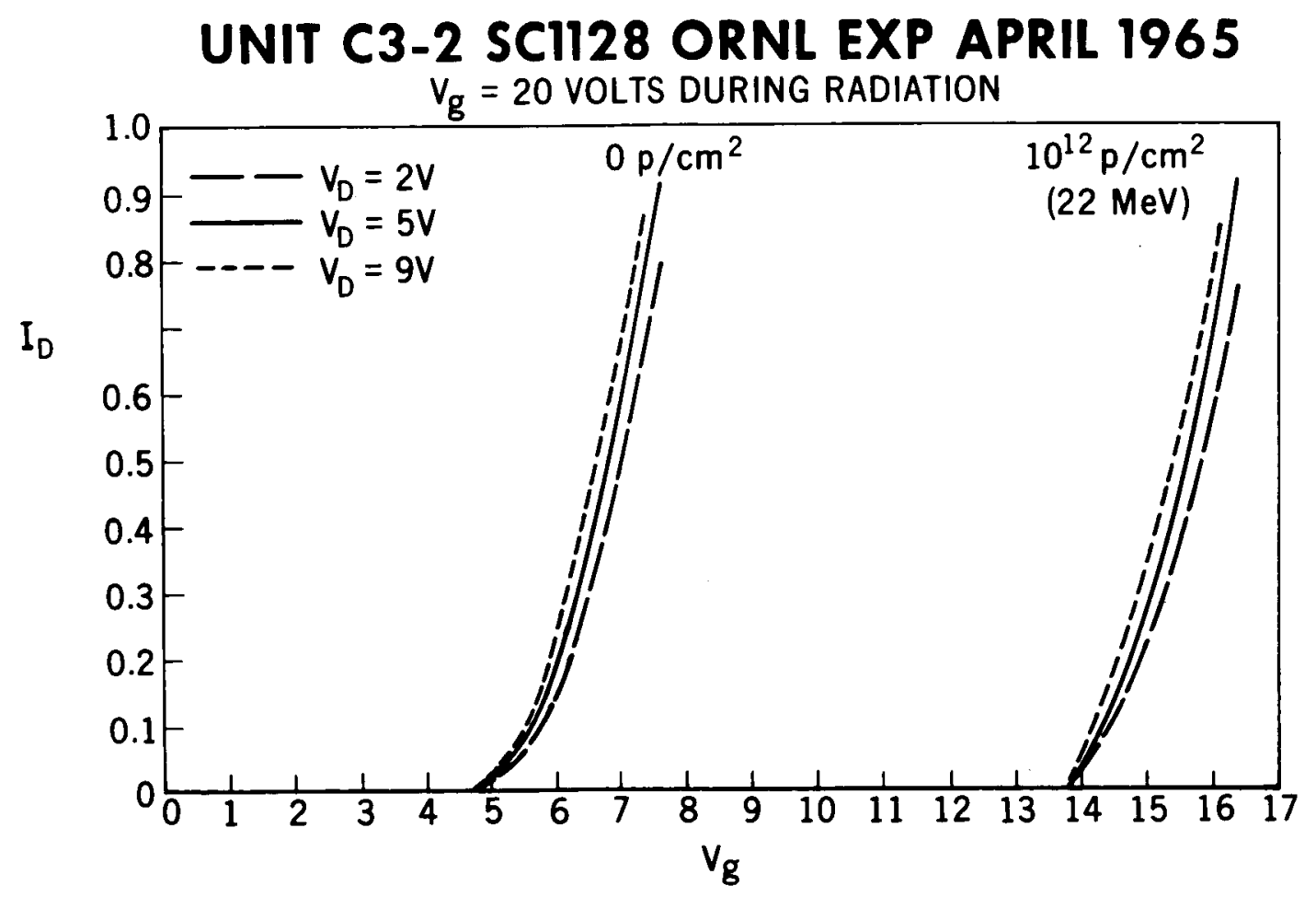

Figure 20 


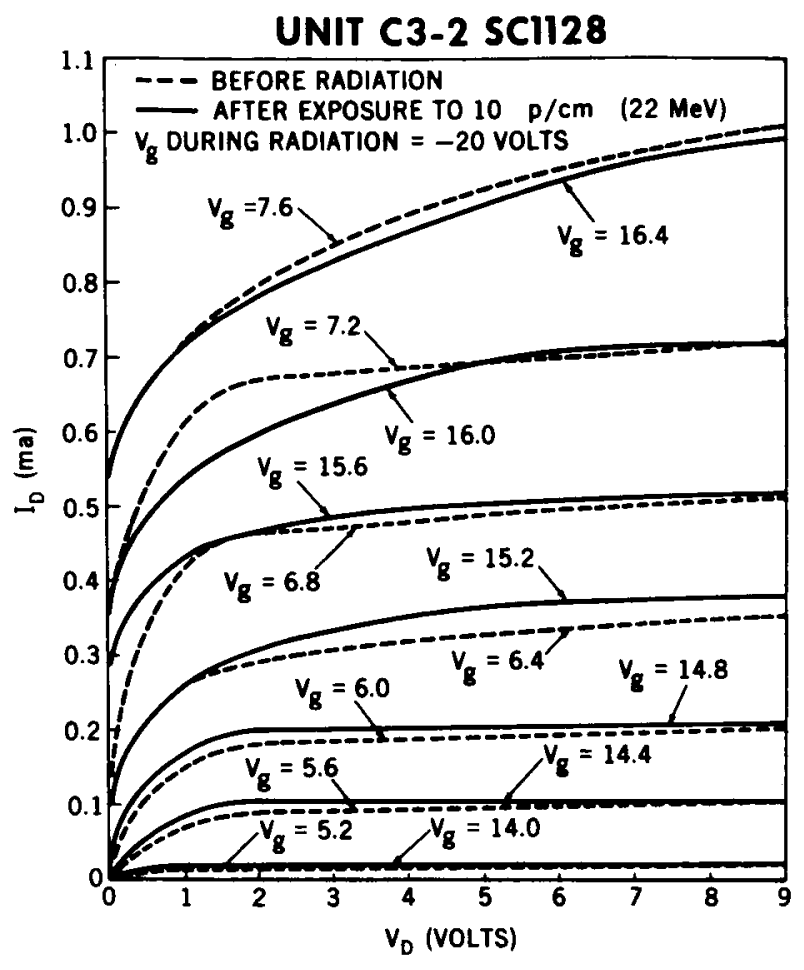

Figure 21

\section{UNIT C3-2}

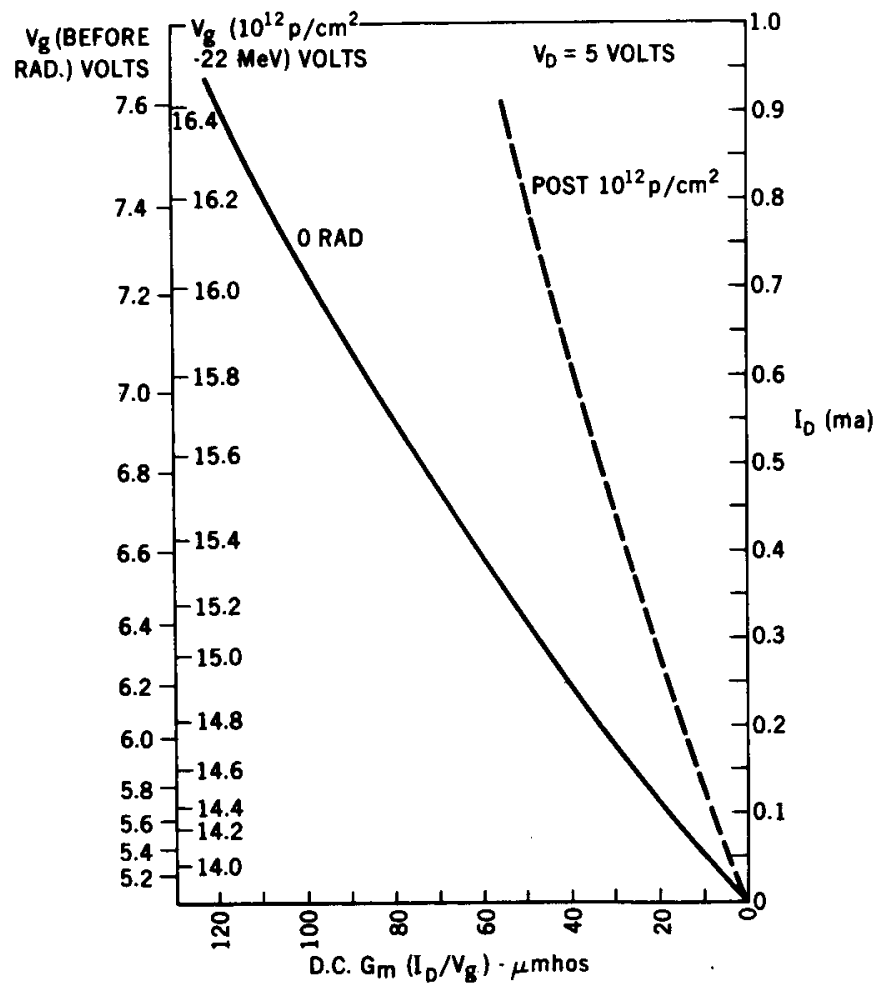




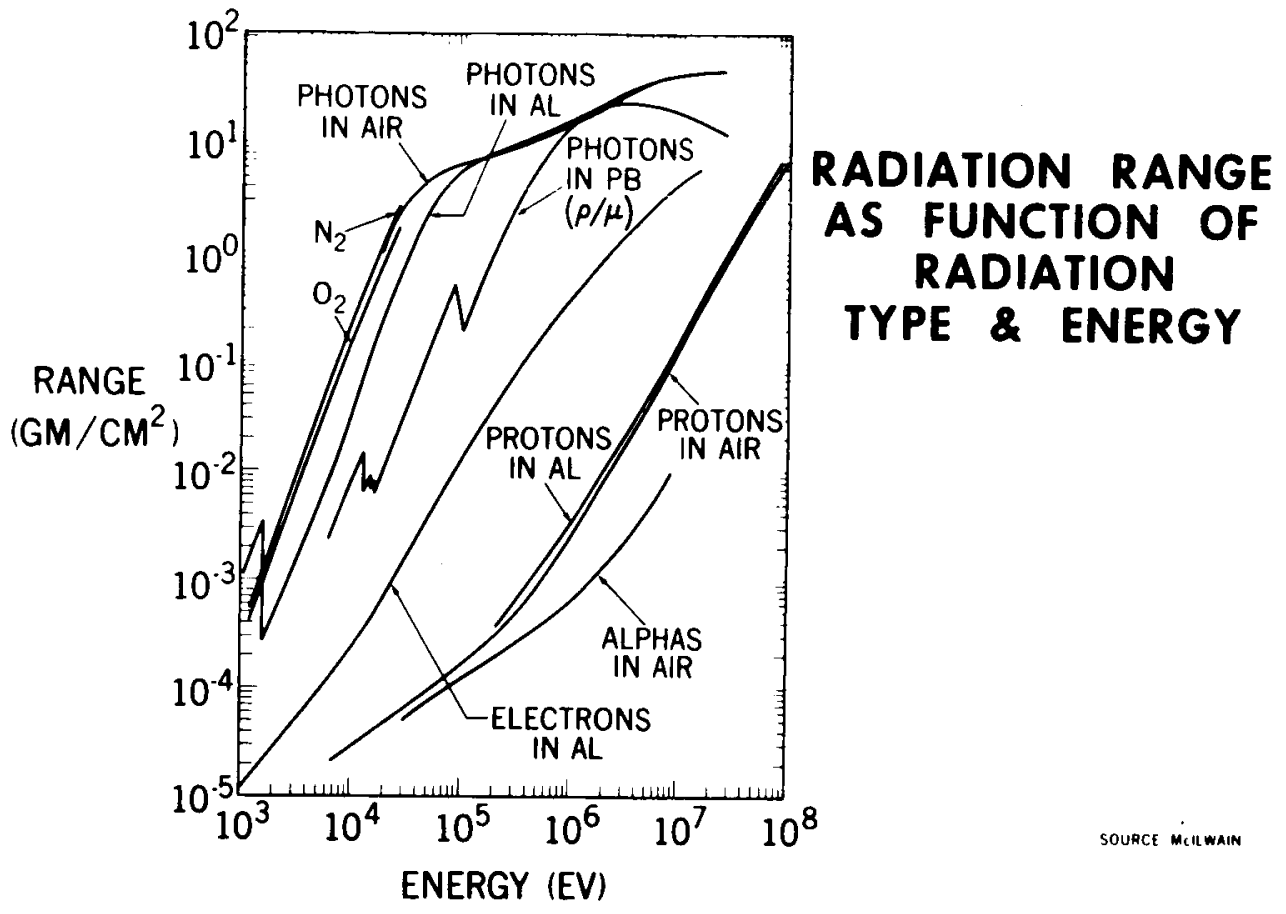

Figure 23

IMP-F TYPE ORBIT COMBINED

EFFECT OF ELECTRON \& PROTON

IRRADIATION AND SHIELDING

(Shielding indicated is in addition to Can.)

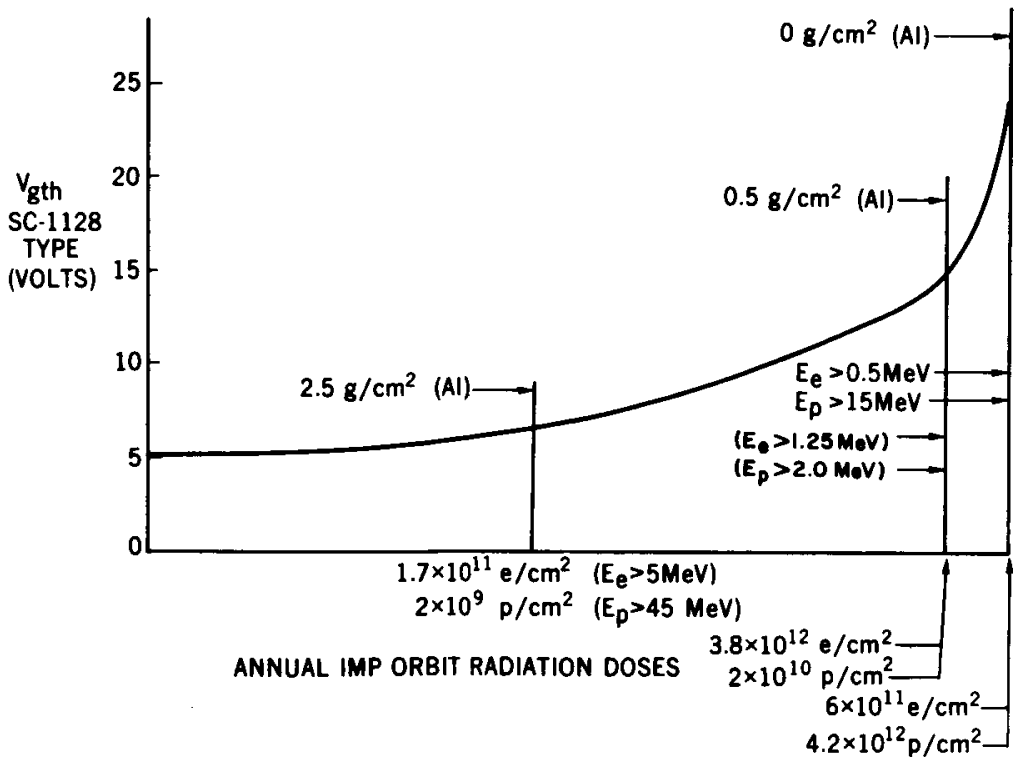

Figure 24 
GATE THRESHOLD VS FLUENCE

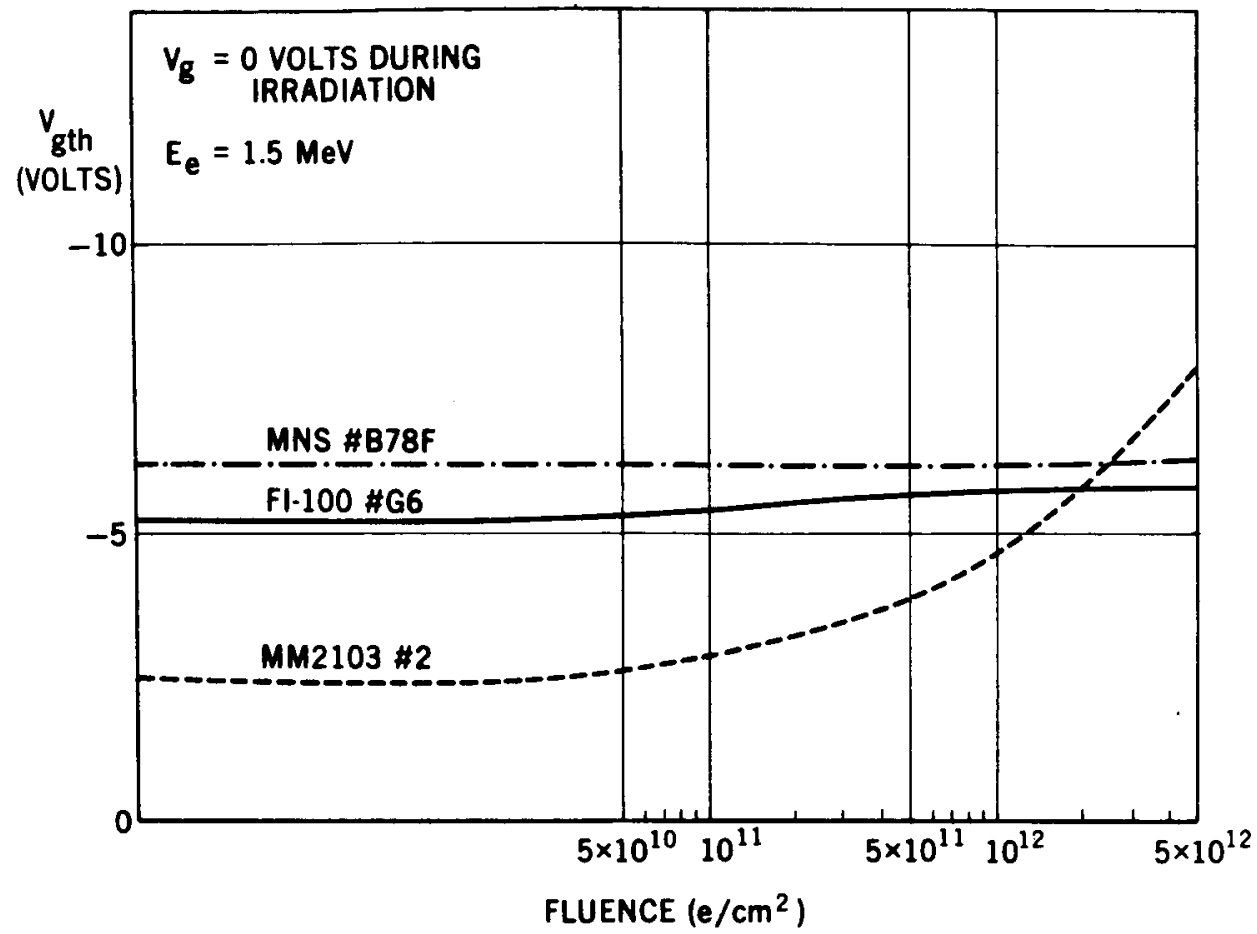

Figure 25

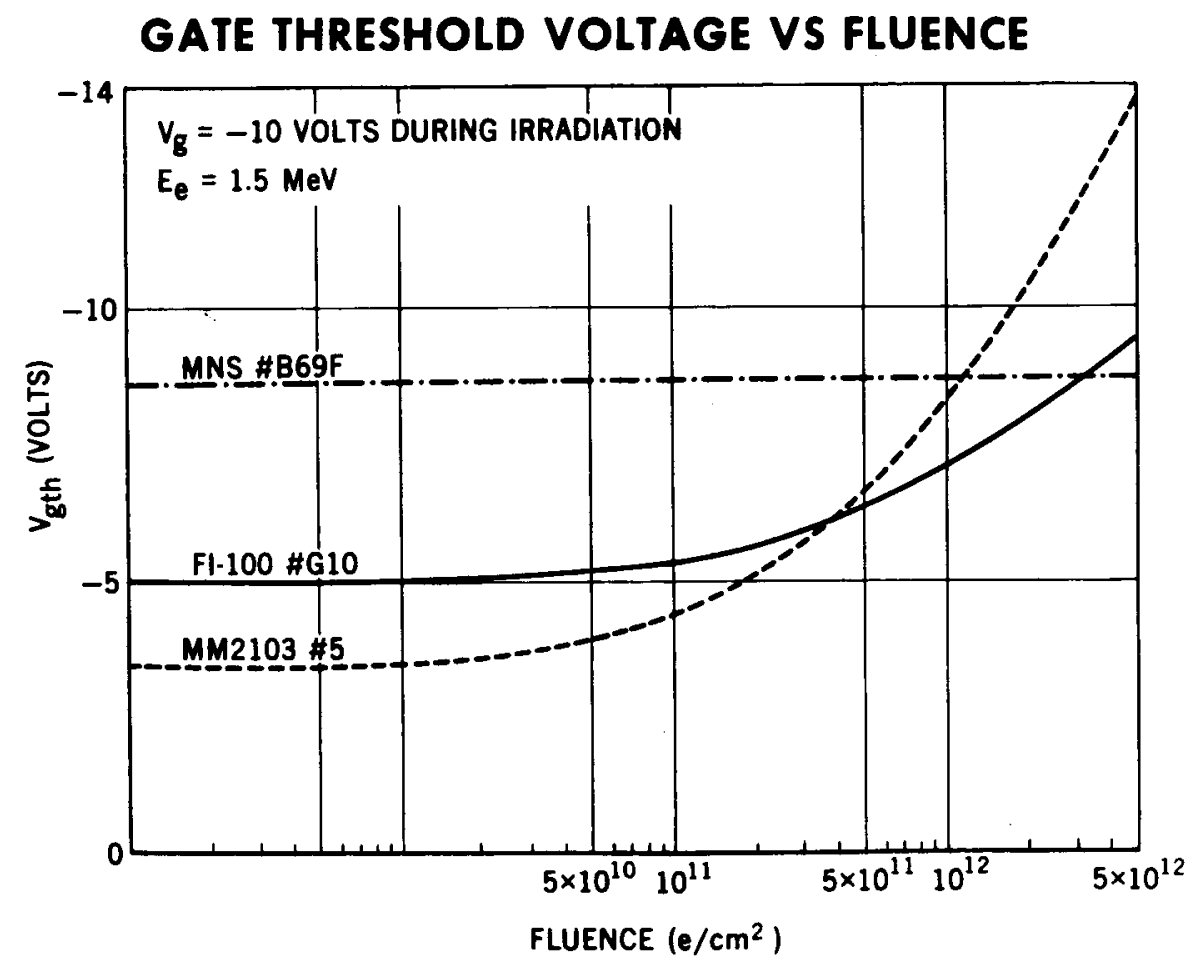

Figure 26 


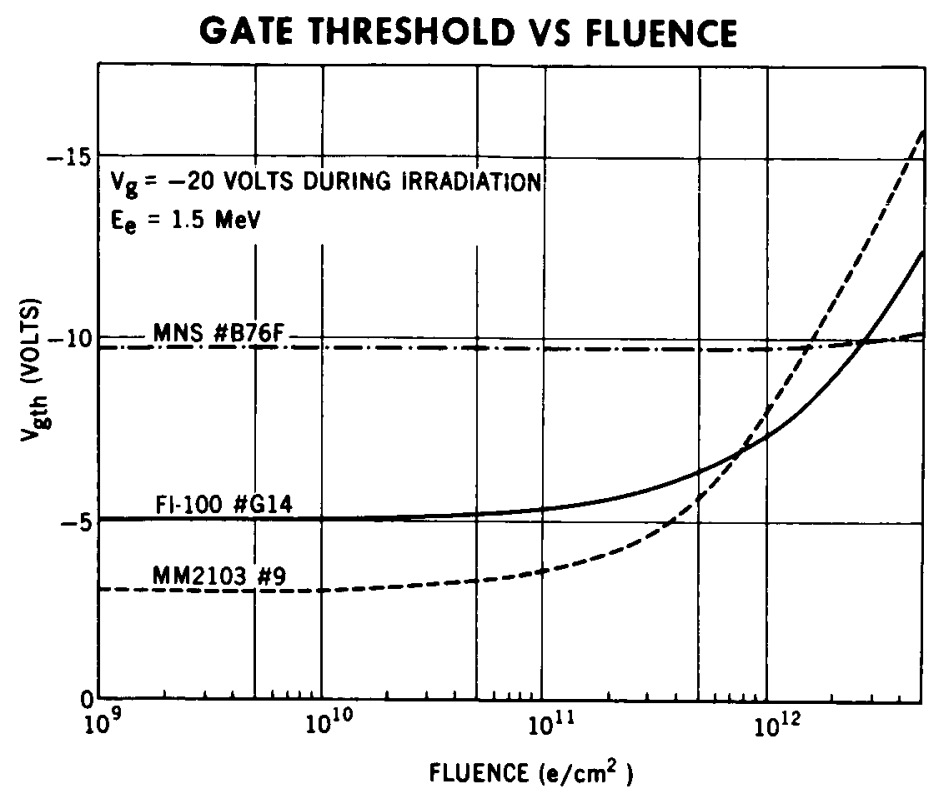

Figure 27

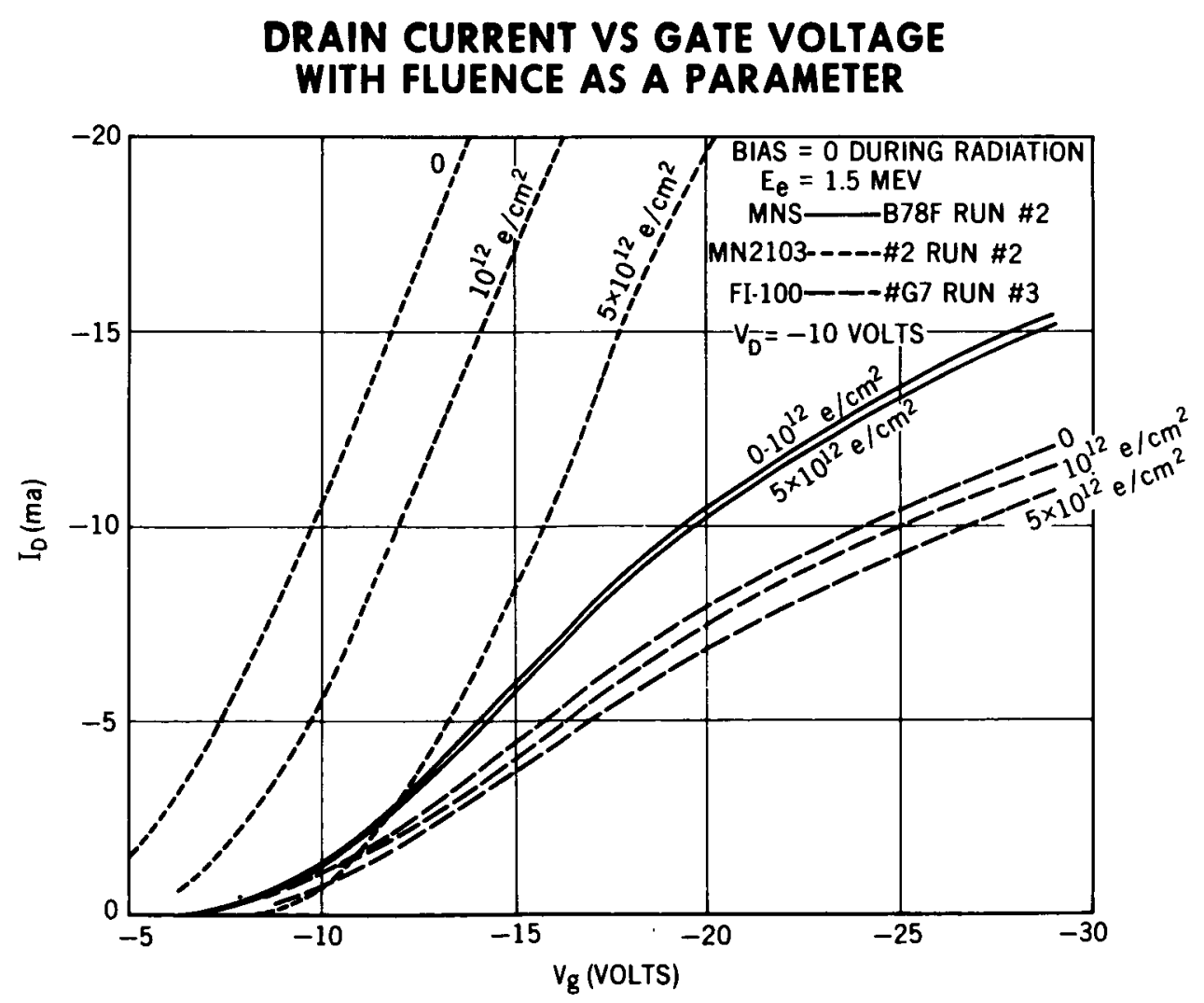

Figure 28 


\section{DRAIN CURRENT VS GATE VOLTAGE}

WITH RADIATION AS A PARAMETER

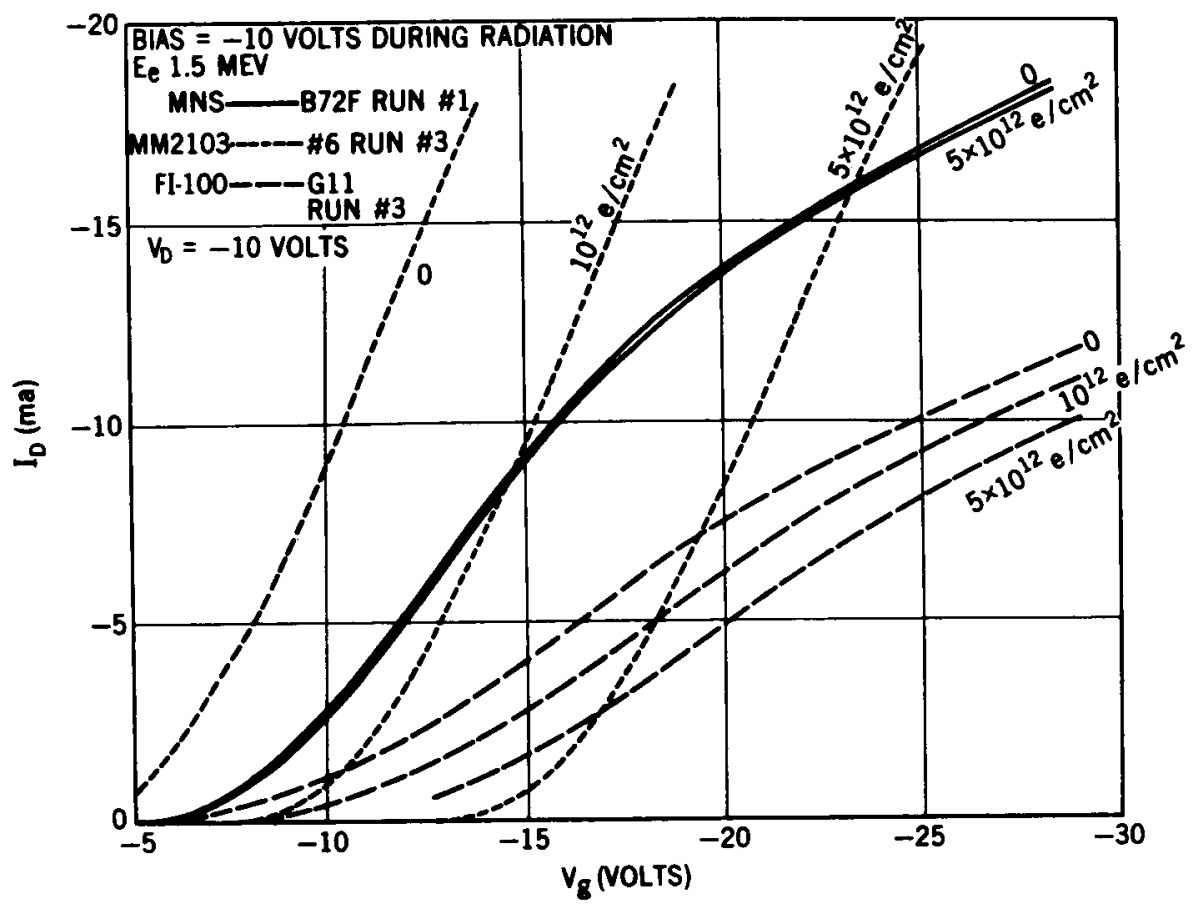

Figure 29

\section{DRAIN CURRENT VS GATE VOLTAGE WITH FLUENCE AS A PARAMETER}

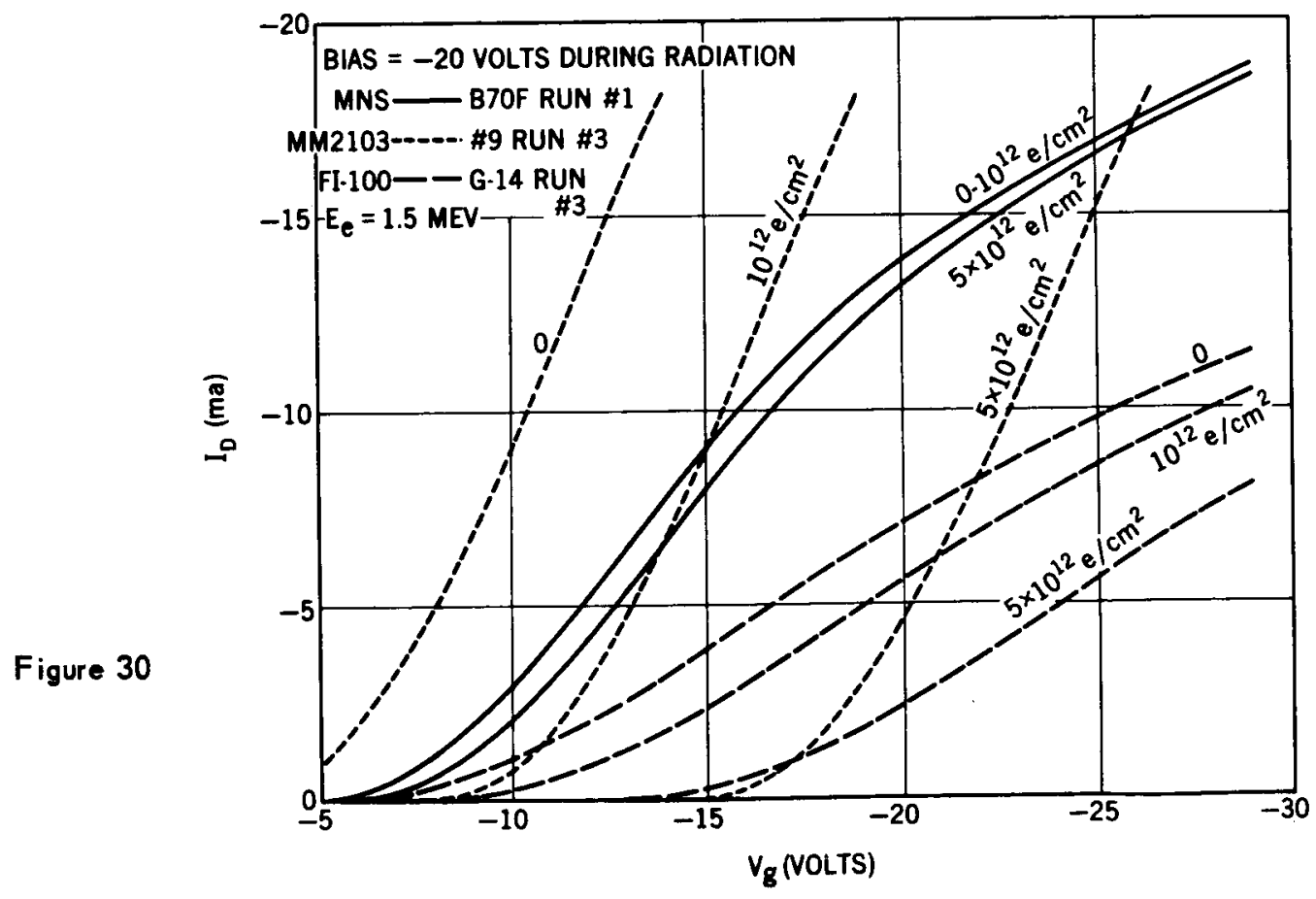




\section{DIRECT CURRENT TRANSCONDUCTANCE VS DRAIN CURRENT WITH FLUENCE AS A PARAMETER}

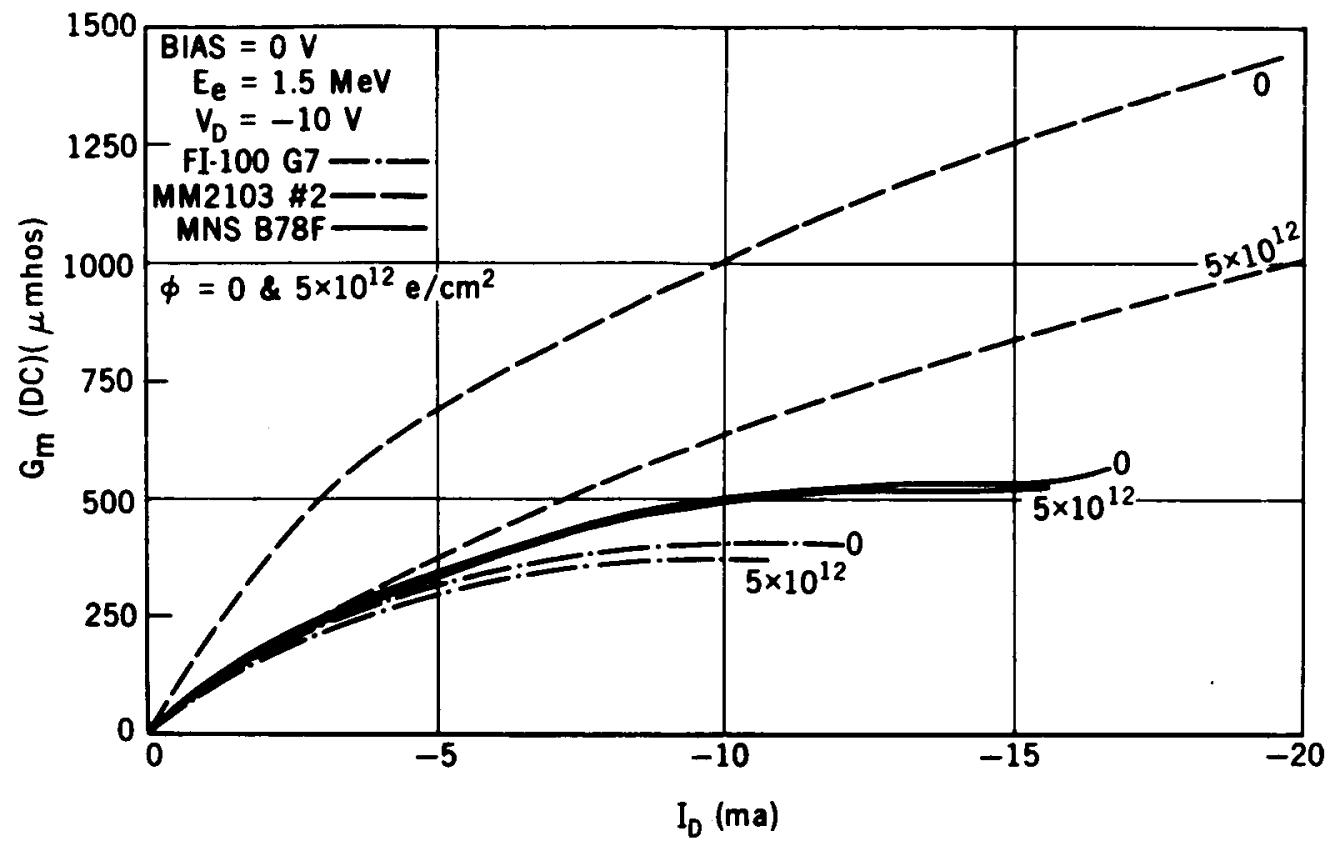

Figure 31

\section{DIRECT CURRENT TRANSCONDUCTANCE VS DRAIN CURRENT WITH FLUENCE AS A PARAMETER}

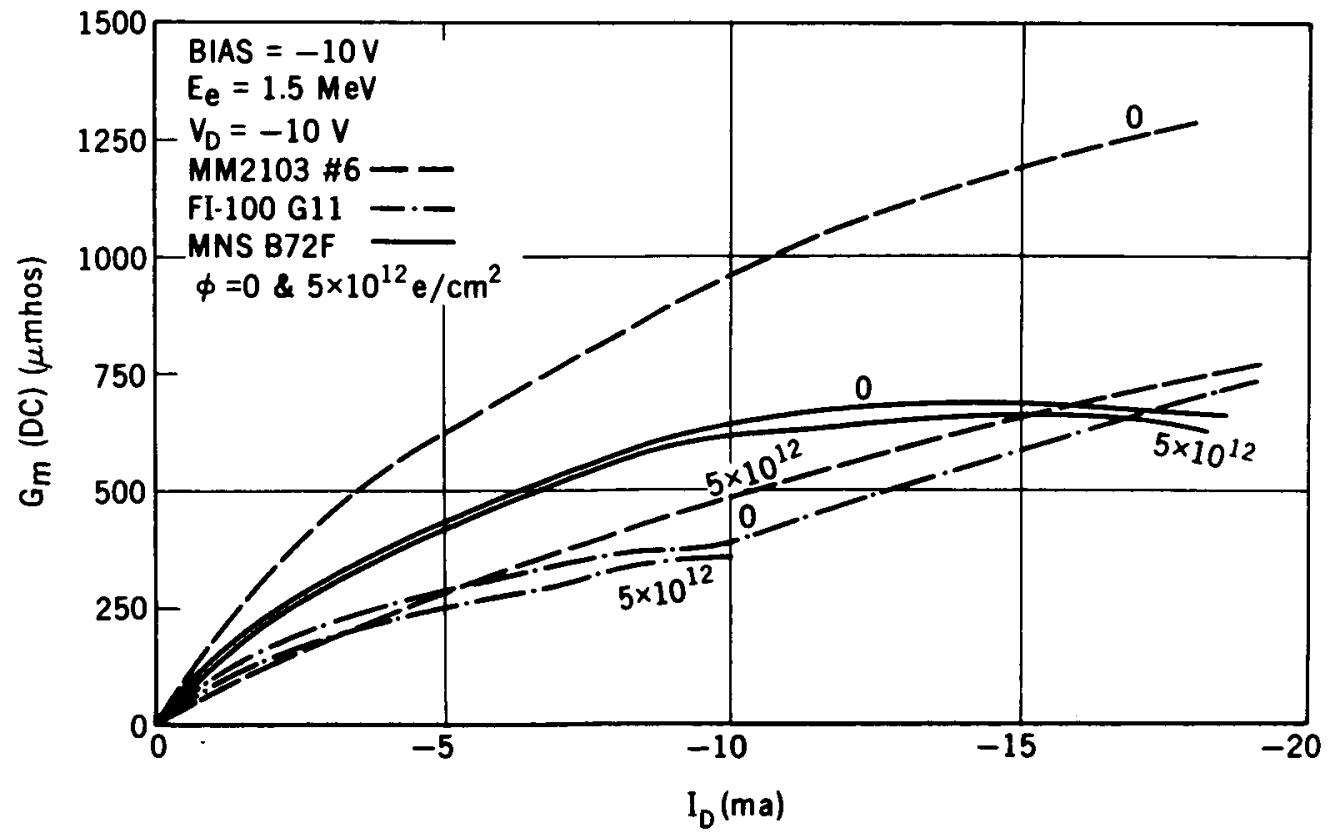

Figure 32 


\section{DIRECT CURRENT TRANSCONDUCTANCE VS DRAIN CURRENT WITH FLUENCE AS A PARAMETER}

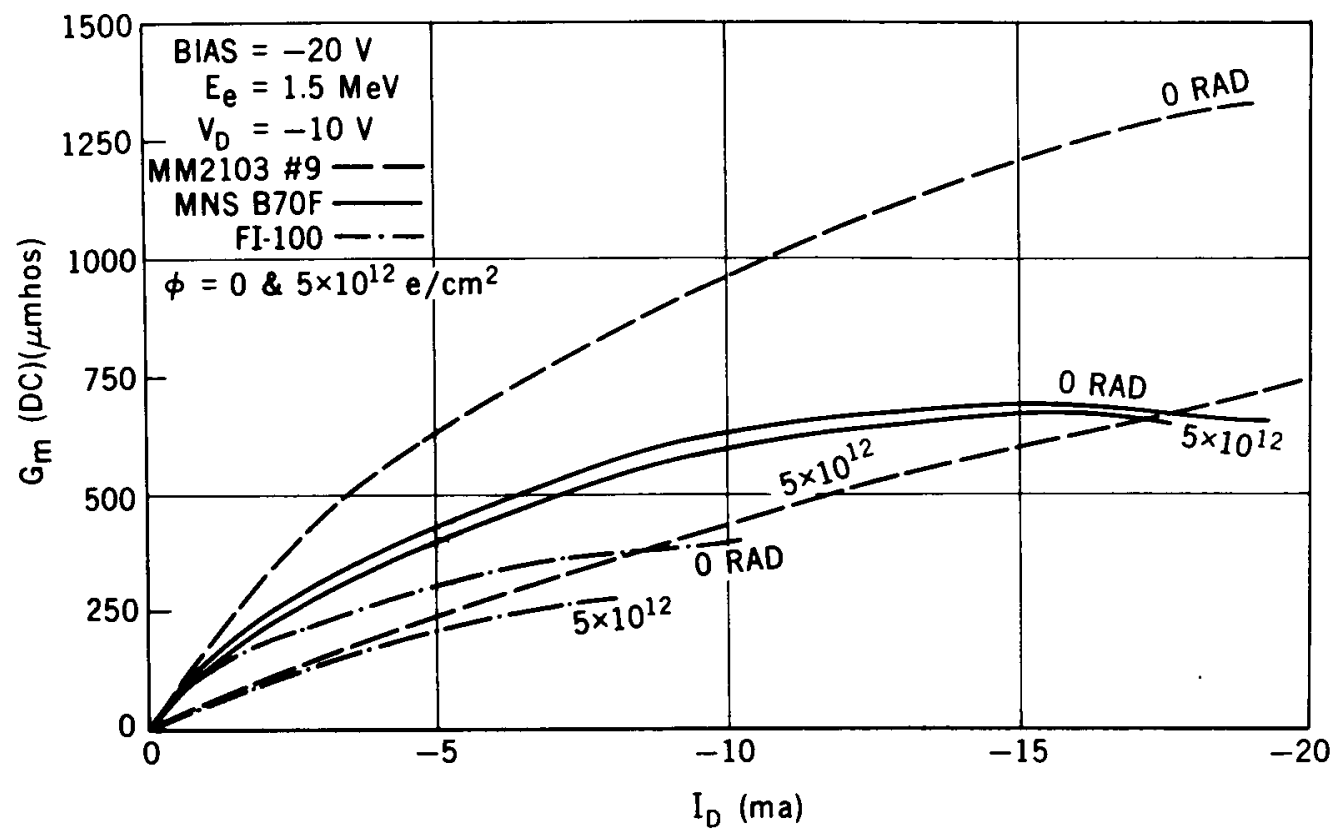

Figure 33

TRANSCONDUCTANCE VS DRAIN CURRENT WITH FLUENCE AS A PARAMETER

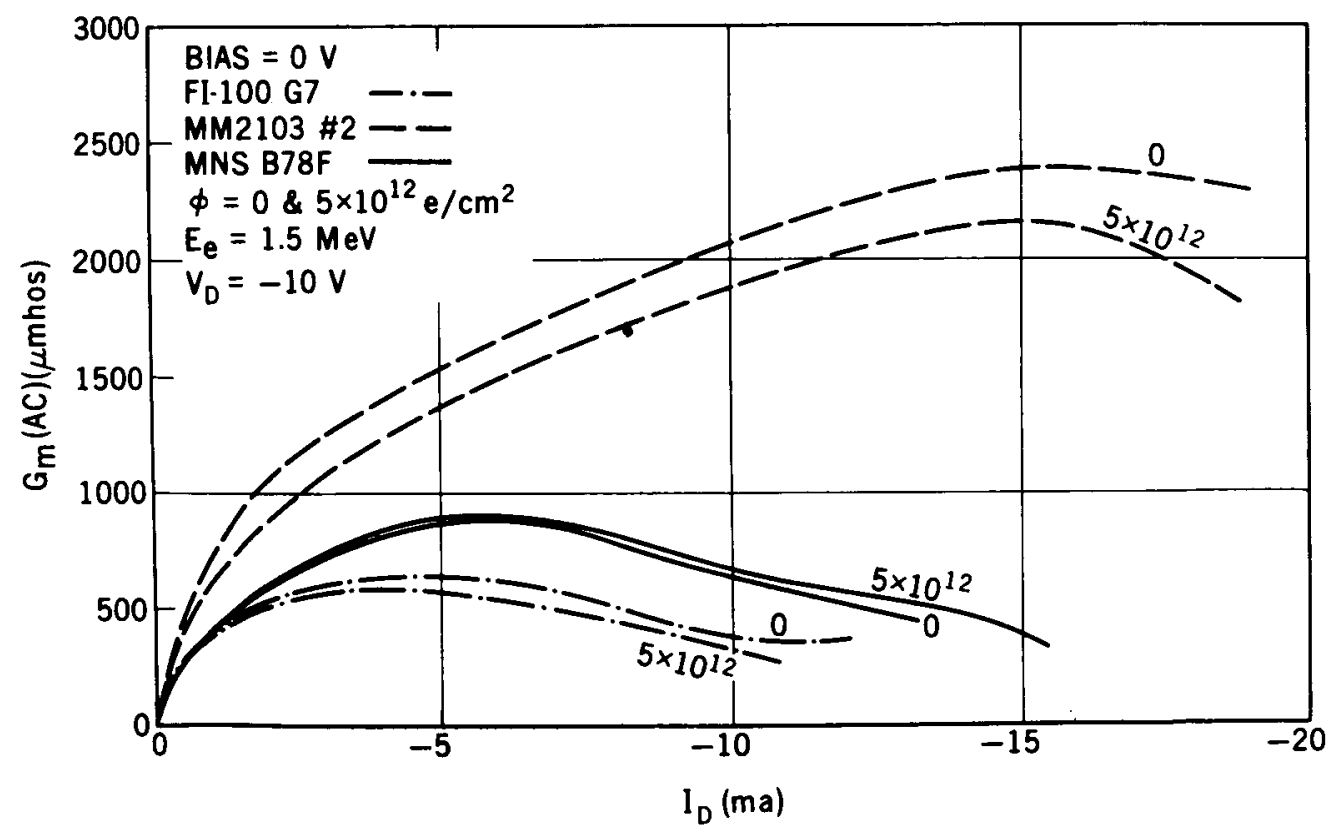

Figure 34 


\section{TRANSCONDUCTANCE VS DRAIN CURRENT WITH FLUENCE AS A PARAMETER}

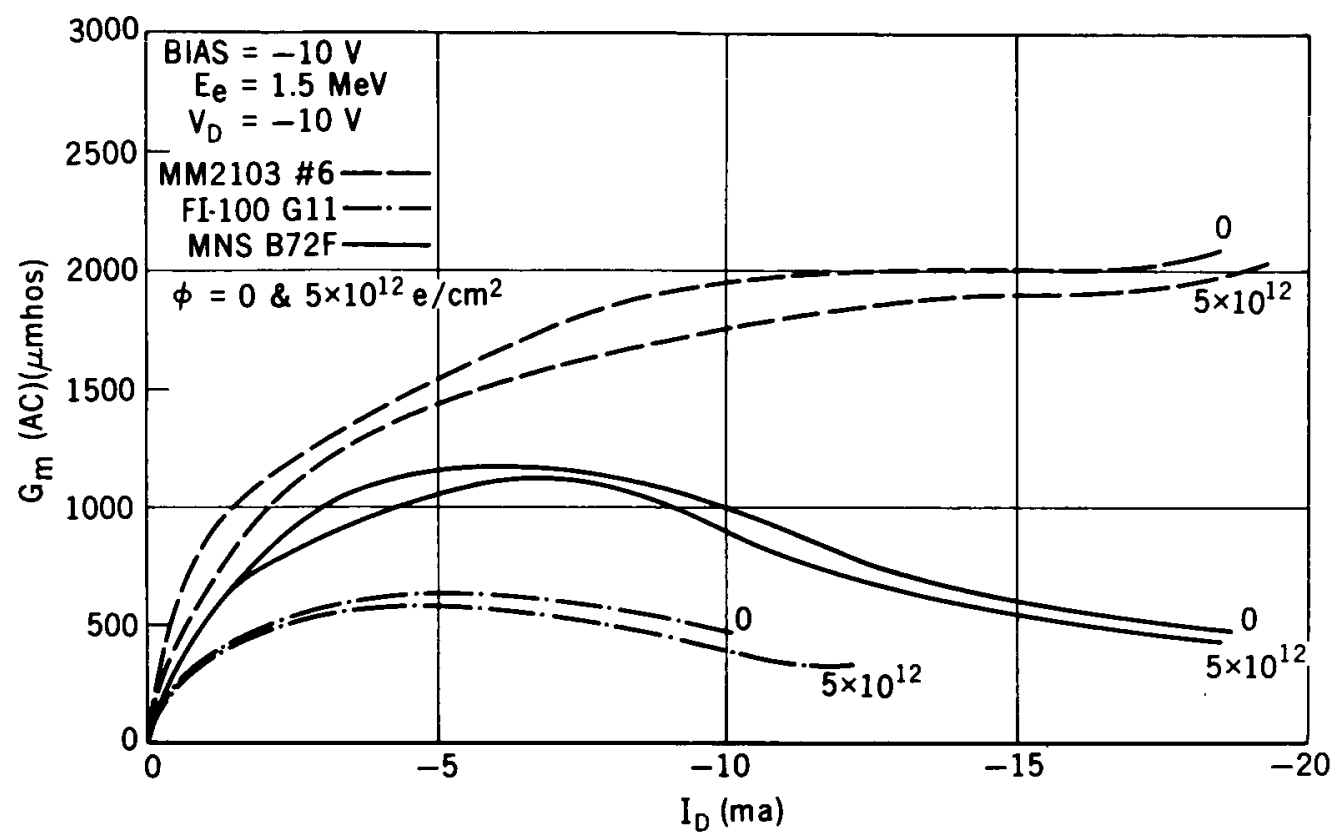

Figure 35

\section{TRANSCONDUCTANCE VS DRAIN CURRENT WITH FLUENCE AS A PARAMETER}

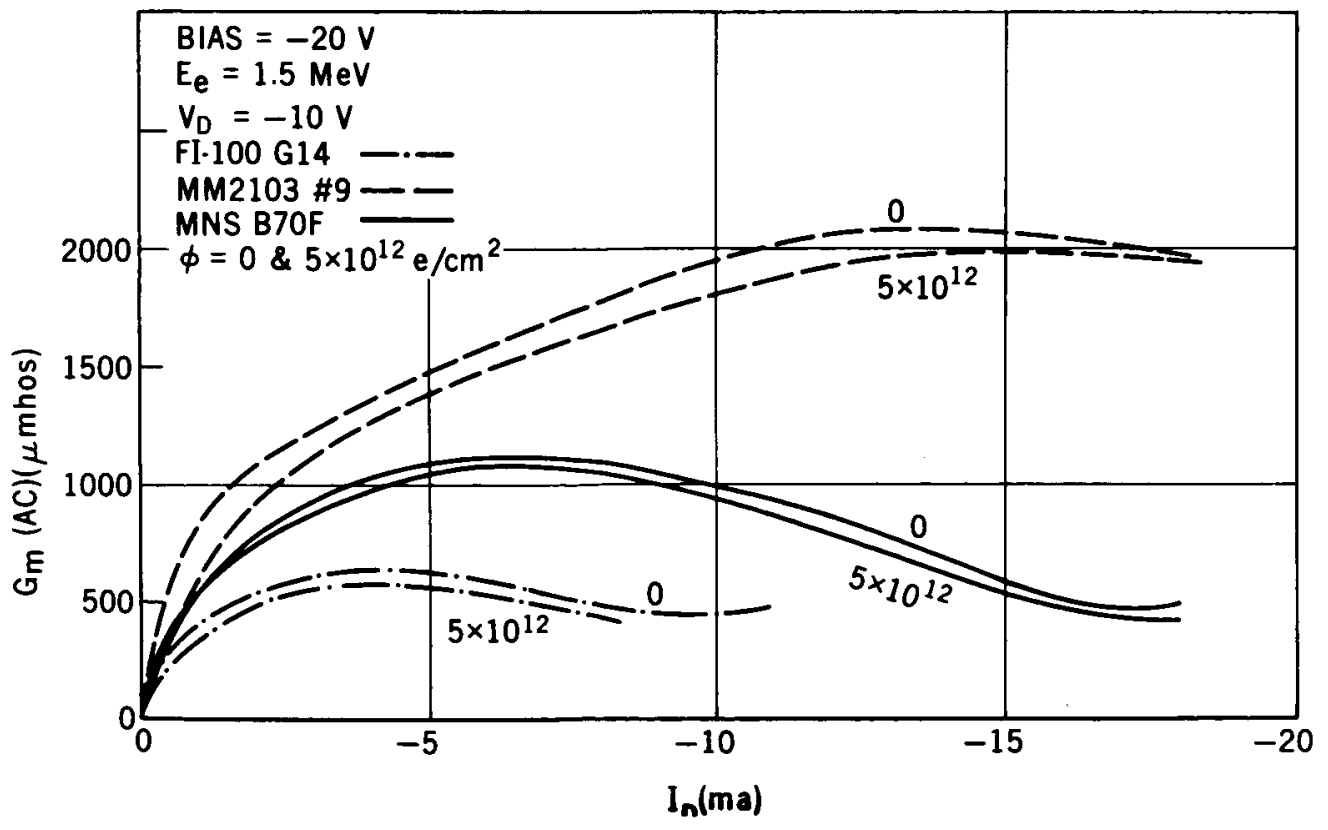

Figure 36 
GATE THRESHOLD VOLTAGE VS FLUENCE

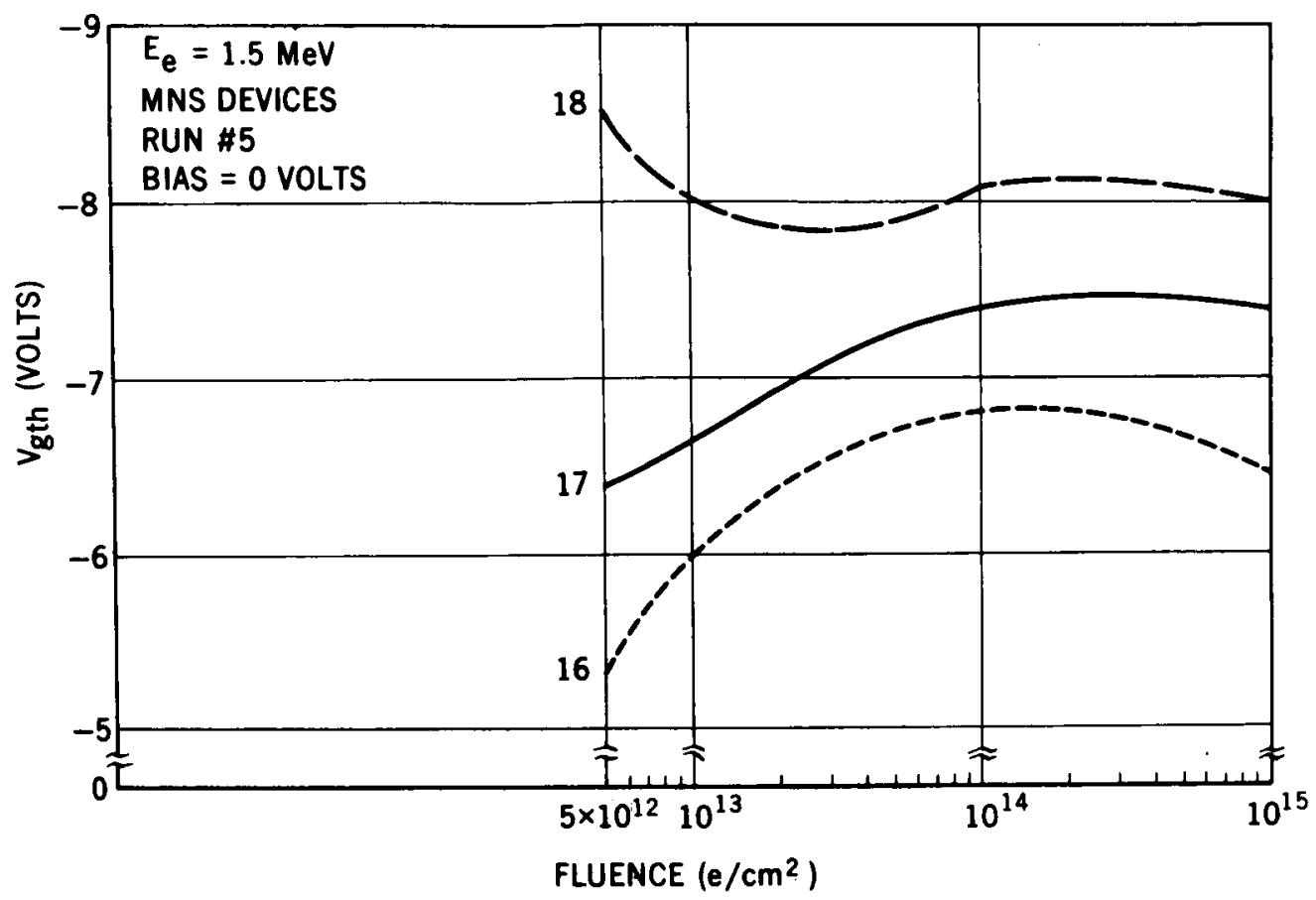

Figure 37

\section{GATE THRESHOLD VOLTAGE VS FLUENCE}

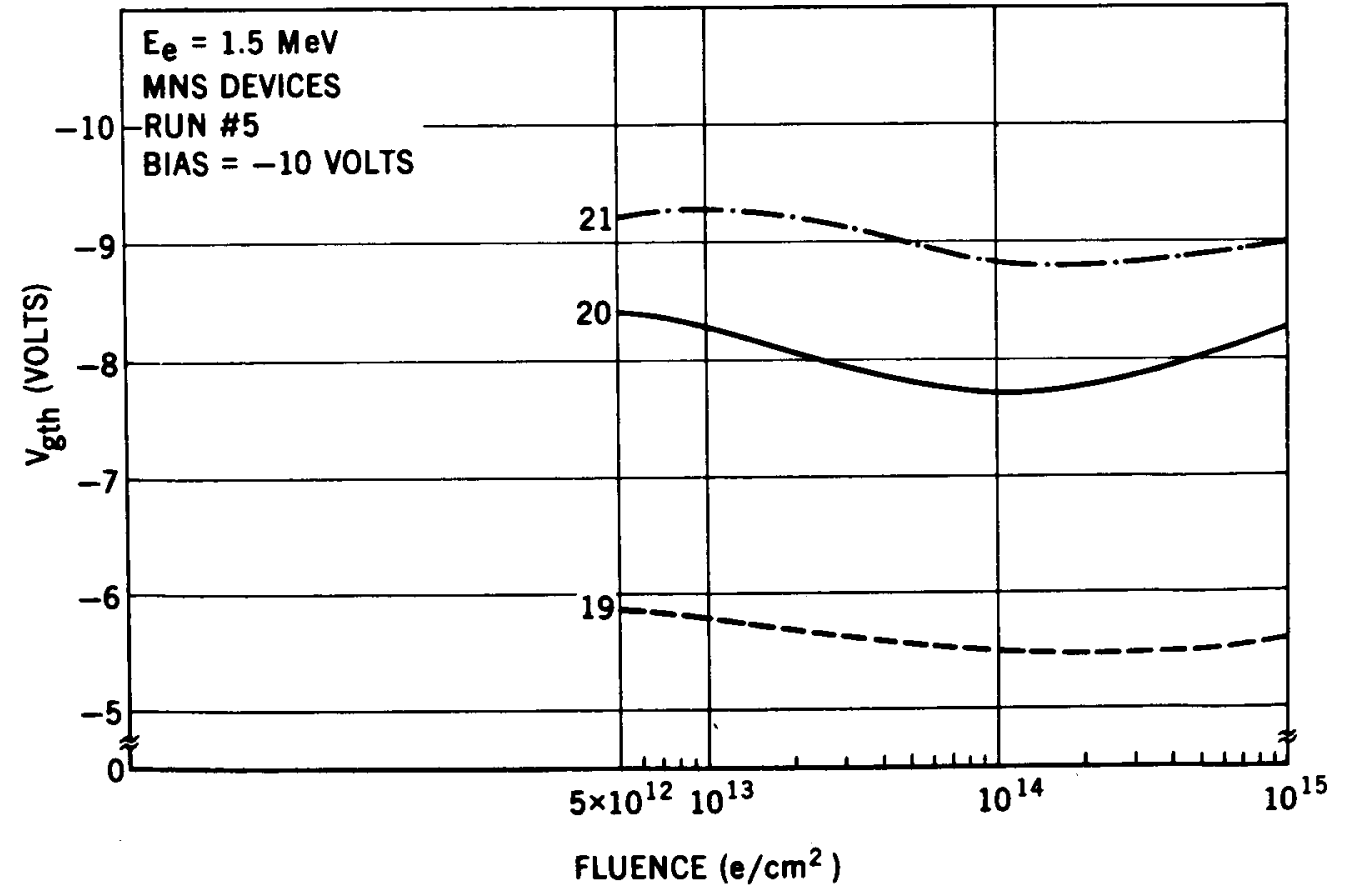

Figure 38 


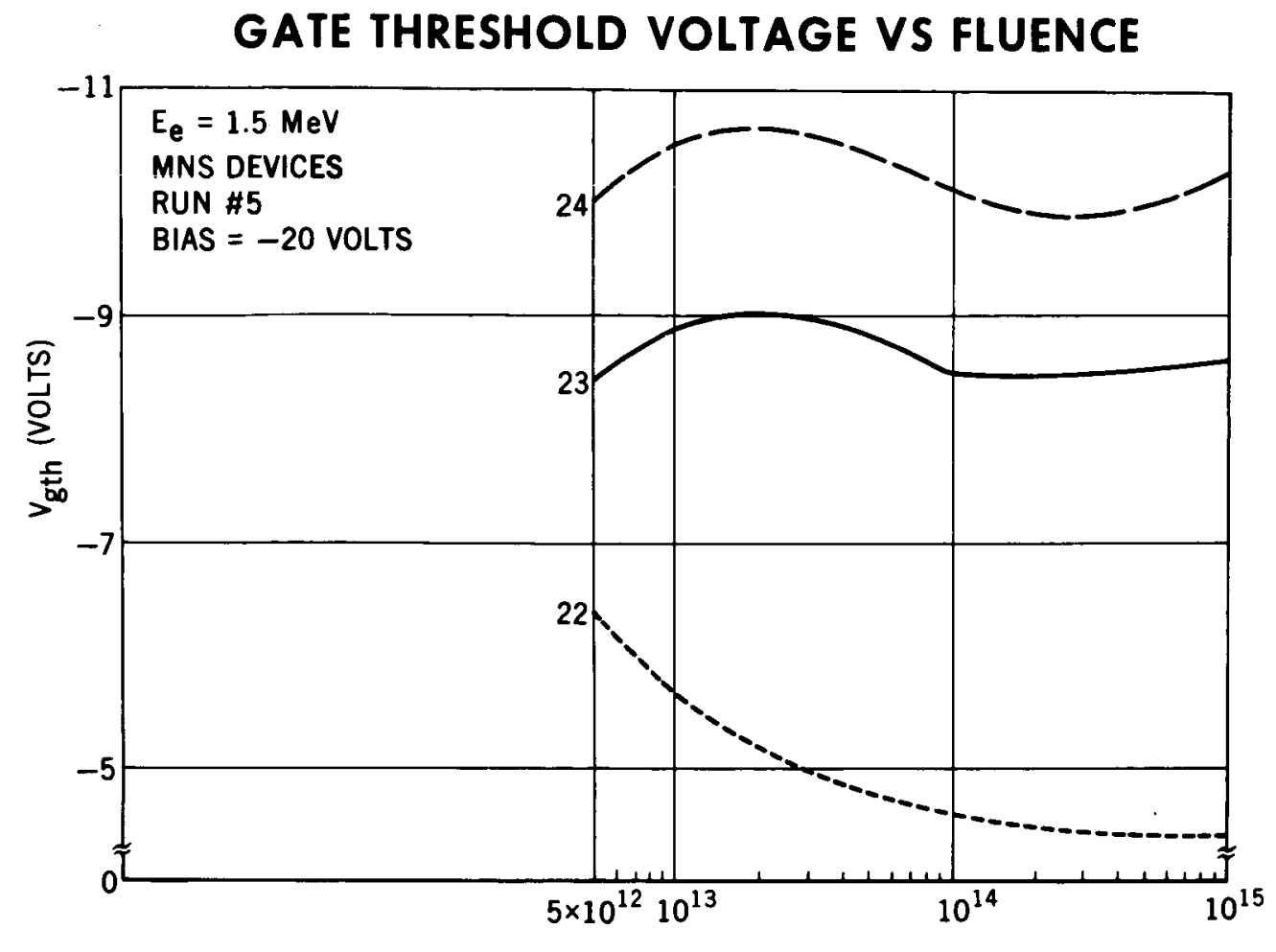

FLUENCE $\left(\mathrm{e} / \mathrm{cm}^{2}\right)$

Figure 39

GATE THRESHOLD VOLTAGE VS FLUENCE

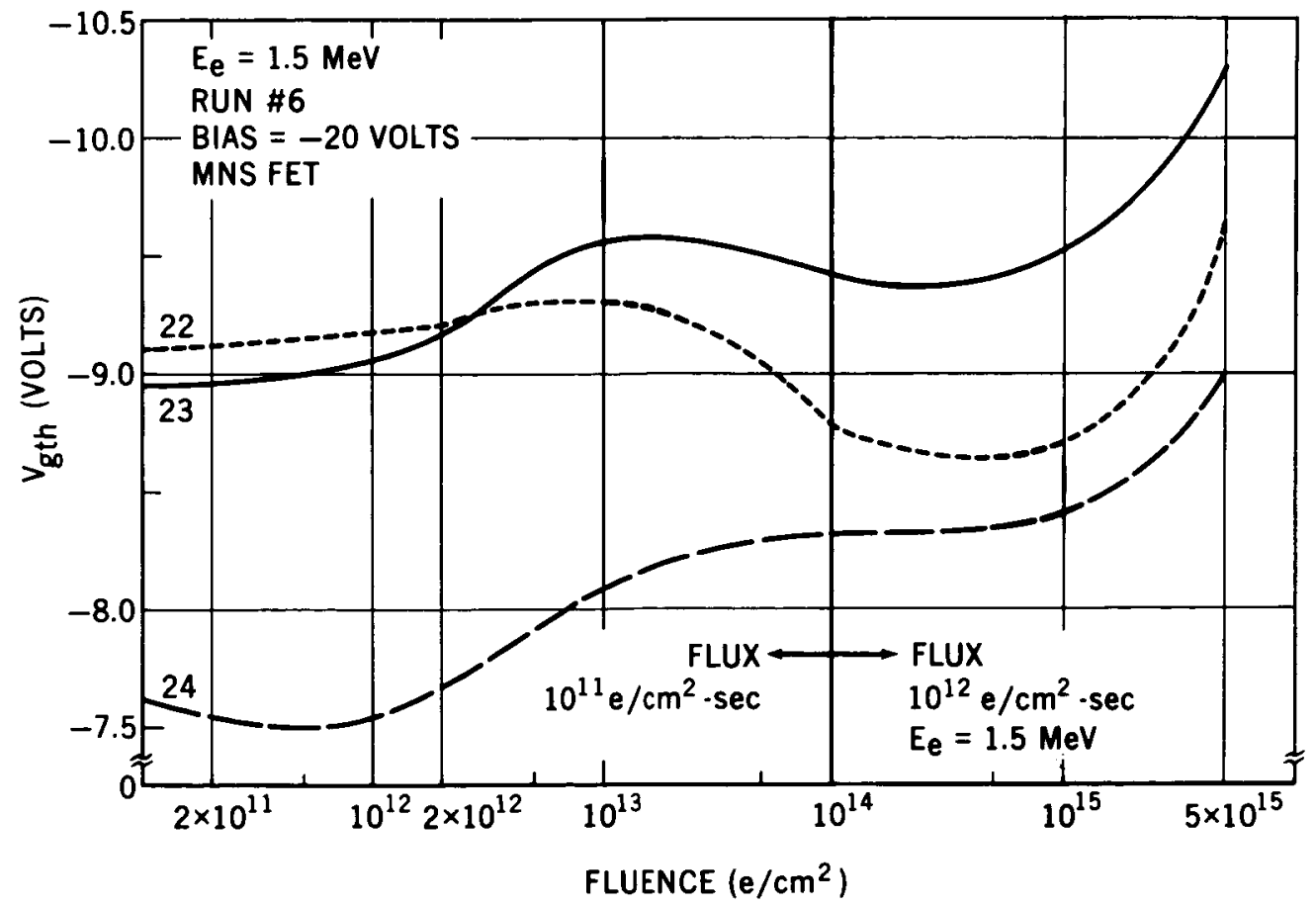

Figure 40 